Article

\title{
Low Molecular Weight Oligomers of Poly(alkylene succinate) Polyesters as Plasticizers in Poly(vinyl alcohol) Based Pharmaceutical Applications
}

\author{
Artemis Palamidi ${ }^{1,2}$, Afroditi Kapourani ${ }^{1}$, Evi Christodoulou ${ }^{2}{ }^{\oplus}$, Panagiotis A. Klonos ${ }^{3}{ }^{\circ}$, \\ Konstantinos N. Kontogiannopoulos ${ }^{1}\left(\mathbb{D}\right.$, Apostolos Kyritsis ${ }^{3}$, Dimitrios N. Bikiaris ${ }^{2}(1)$ \\ and Panagiotis Barmpalexis $1, *$ (D)
}

Citation: Palamidi, A.; Kapourani, A.; Christodoulou, E.; Klonos, P.A.; Kontogiannopoulos, K.N.; Kyritsis, A.; Bikiaris, D.N.; Barmpalexis, P. Low Molecular Weight Oligomers of Poly(alkylene succinate) Polyesters as Plasticizers in Poly(vinyl alcohol) Based Pharmaceutical Applications Polymers 2021, 13, 146. https://doi. org $/ 10.3390 /$ polym13010146

Received: 9 December 2020 Accepted: 28 December 2020 Published: 1 January 2021

Publisher's Note: MDPI stays neutral with regard to jurisdictional clai$\mathrm{ms}$ in published maps and institutional affiliations.

Copyright: (C) 2021 by the authors. Licensee MDPI, Basel, Switzerland. This article is an open access article distributed under the terms and conditions of the Creative Commons Attribution (CC BY) license (https:// creativecommons.org/licenses/by/ $4.0 /)$.
1 Department of Pharmaceutical Technology, School of Pharmacy, Aristotle University of Thessaloniki, 54124 Thessaloniki, Greece; artemispalamidi@gmail.com (A.P.); akapourag@pharm.auth.gr (A.K.); kkontogi@cheng.auth.gr (K.N.K.)

2 Laboratory of Polymer Chemistry and Technology, Department of Chemistry, Aristotle University of Thessaloniki, 54124 Thessaloniki, Greece; evicius@gmail.com (E.C.); dbic@chem.auth.gr (D.N.B.)

3 Department of Physics, Zografou Campus, National Technical University of Athens, 15780 Athens, Greece; panos48al@gmail.com (P.A.K.); akyrits@central.ntua.gr (A.K.)

* Correspondence: pbarmp@pharm.auth.gr; Tel.: +30-2310-997629

\begin{abstract}
The plasticizing effect of three low molecular weight oligomers of aliphatic poly(alkylene succinate) polyesters, namely poly(butylene succinate) (PBSu), poly(ethylene succinate) (PESu), and poly(propylene succinate) (PPSu), on partially hydrolyzed poly(vinyl alcohol) (PVA) used in melt-based pharmaceutical applications, was evaluated for the first time. Initially, the three aliphatic polyesters were prepared by the melt polycondensation process and characterized by differential scanning calorimetry (DSC), ${ }^{1} \mathrm{H}$ NMR, intrinsic viscosity, and size exclusion chromatography (SEC). Subsequently, their effect on the thermophysical and physicochemical properties of PVA was thoroughly evaluated. According to the obtained results, PVA was completely miscible with all three polyesters, while PESu induced PVA's thermal degradation, with the phenomenon starting from $\sim 220^{\circ} \mathrm{C}$, in contrast to PBSu and PPSu, where a thermal profile similar to PVA was observed. Furthermore, molecular interactions between PVA and the prepared poly(alkylene succinate) polyesters were revealed by DSC, ATR-FTIR, and molecular dynamics simulations. Finally, melt flow index (MFI) measurements showed that, in contrast to PBSu, the use of PESu or PPSu significantly improved PVA's melt flow properties. Hence, according to findings of the present work, only the use of low molecular weight PPSu is suitable in order to reduce processing temperature of PVA and improve its melt flow properties (plasticizing ability) without affecting its thermal decomposition.
\end{abstract}

Keywords: aliphatic polyesters; biodegradable polymers; poly(vinyl alcohol); fusion-based pharmaceutical processes; thermal stability; melt flowability

\section{Introduction}

The poor aqueous solubility (and hence the restricted bioavailability) of the newly developed Active Pharmaceutical Ingredients (APIs) has been a major obstacle for the development of efficient drug formulations. Specifically, it is estimated that more than $50 \%$ of APIs, which are nowadays used, belong to the Biopharmaceutical Classification System class II (BCS class II), presenting poor aqueous solubility [1]. In order to overcome this problem, various approaches have been proposed, including salt formation, co-crystallization, particle size reduction, prodrug formation, use of cosolvents or surfactants, cyclodextrin complexation, etc. [2-4]. Out of them, amorphous solid dispersions (ASDs) were proved to be one of the most promising techniques to increase the apparent solubility and dissolution of APIs, and thus their therapeutic effect [5]. In ASDs systems, the API is amorphously 
dispersed within a hydrophilic (usually polymeric) matrix carrier or a mixture of carriers [6,7]. Several different approaches have been proposed for the manufacturing of ASDs, which can be categorized into two general classes: the solvent-based methods and the fusion-based methods [8]. Among them, fusion or melt -based methods such as hot-melt extrusion and melt mixing, have gained increased attention and are widely selected in the pharmaceutical arena, as they offer several advantages such as shorter time to achieve the final product and the elimination of solvent use [9-11].

Typical melt-based methods consist of two major subprocesses: the co-melting of the API with the carrier (or the carriers) at pre-optimized temperature, followed by the rapid cooling of the molten mixture so a one-phase system is formed [10,11]. The preparation and the physical stability of the ASDs are strongly related to the matrix-carrier's properties, such as glass transition temperature $\left(\mathrm{T}_{\mathrm{g}}\right)$, hydrophilicity, plasticizing ability, etc., and API's attributes, including glass transition temperature, $\log P$ value, hydrophilicity, etc. Furthermore, both the ratio of API to polymer/plasticizer system and the API-carrier miscibility affect the formation and the physical stability of the final system [12-14]. As a result, the types and grades of polymers that can be utilized in common melt-based methods, such as hot-melt extrusion (HME), are often limited by physicochemical, thermophysical, or rheological factors. Therefore, in order to improve the safety and efficacy of such drug formulations, the initial screening and assessment of the polymeric carrier must be carefully carried out [14,15].

A representative example of a polymer for such melt-based applications is polyvinyl alcohol (PVA). PVA is typically a semi-crystalline, water-soluble polymer, which is used in a wide range of industrial, commercial, medical, and food applications [16]. The physical characteristics of PVA depend on the extent or degree of its hydrolysis, specifically whether it is full or partial, which in turn dictates the classification of PVA into two groups, namely, (a) partially hydrolyzed and (b) fully hydrolyzed [17]. The degree of PVA's hydrolysis is considered as a measure of the ratio of polyvinyl alcohol to polyvinyl acetate groups and results in PVA products of differing molecular weights, solubility, flexibility, tensile strength, and swelling-ability, which in turn can impact the performance of pharmaceutical formulations [18,19]. Its hydrophilic, non-toxic [17], non-carcinogenic and biodegradable [20] nature make PVA, and especially partially hydrolyzed PVA, an interesting polymer for pharmaceutical applications. However, the use of PVA as a matrix-carrier in melt-based pharmaceutical applications is considered a significant challenge for pharmaceutical formulation scientists, due to the fact that the polymer is not extrudable at temperatures below its melting point, whilst it is a highly thermal sensitive compound with thermal degradation taking place near its melting point [21,22].

Looking to overcome these drawbacks, recent research studies have shown that the addition of plasticizers, or lubricants, results in significant improvement of PVA's melt flowability below its melting point [21-23]. In this context, a previous study of ours showed that the selection of suitable plasticizers for PVA fusion-based pharmaceutical applications is a crucial procedure and needs extreme attention when designing an efficient pharmaceutical formulation system, such as ASDs [24]. Based on these findings, the study concludes that there is still a lot of ground to be covered in this area, due to the endless urge for new and efficient plasticizers, able to reduce PVA's processing temperature, improve its melt flow characteristics, and maintain its acceptable thermal stability.

On this set framework, the scope of the present study was to evaluate, for the first time, the use of three poly(alkylene succinate) polyesters as suitable pharmaceutical plasticizers in melt-based pharmaceutical applications utilizing partially hydrolyzed PVA as a matrix carrier (such as the formation of PVA-based ASDs). Generally, biodegradable polymers have attracted considerable attention last decades due to their potential applications as green materials, contributing to lower environmental pollution. The examined three aliphatic polyesters present favorable features of controllable biodegradation rate, biocompatibility, and high processability $[25,26]$. Hence, they are appropriate for medical and biomedical applications, including drug delivery systems. In the present study, the effect 
of poly(ethylene succinate) (PESu), poly(propylene succinate) (PPSu), and poly(butylene succinate) (PBSu) on the thermo-physical and physicochemical properties of PVA was evaluated via differential scanning calorimetry (DSC), thermogravimetric analysis (TGA), hot stage polarized light microscopy (HSM), powder X-ray diffraction (pXRD), and attenuated total reflectance (ATR) FTIR analyses. In addition, the plasticizing ability of the prepared polyesters on the melt-flow properties of PVA was also evaluated, while molecular dynamics (MD) simulations were employed for the in-depth understanding of the physicochemical phenomena occurring during the co-melting process of PVA with the selected polyesters.

\section{Materials and Methods}

\subsection{Materials}

Partially hydrolyzed PVA (Parteck ${ }^{\circledR}$ MXP, lot no. F2016164812) with 87-89\% hydrolysis grade and MW approx. 32,000 Da, was obtained from Merck Millipore (Merck Millipore, Burlington, Massachusetts, United States). Succinic acid (SA) (purum 99\%+), ethylene glycol (anhydrous, 99.8\%) used in the synthesis of polyesters were purchased from Sigma-Aldrich, 1,3-propanediol (purum 99.6 + \%), and 1,4-Butanediol (assay 99\%) were purchased from Alfa Aeser, (Kandel, Germany). Antimony trioxide $\left(\mathrm{Sb}_{2} \mathrm{O}_{3}, 99.99 \%\right)$, used as catalyst, was of analytical grade, and it was purchased from Aldrich Co. (Chemie $\mathrm{GmbH}$, Steinheim, Germany). All other reagents were of analytical or pharmaceutical grade and used as received.

\subsection{Synthesis of Poly(alkylene succinate) Polyesters}

Synthesis of aliphatic polyesters was performed following the two-stage melt polycondensation method (esterification and polycondensation) in a glass batch reactor $[27,28]$. The reaction scheme is shown in Figure 1.

In brief, the proper amount of succinic acid and appropriate diol, in a molar ratio 1/1.1, and the catalyst $\mathrm{Sb}_{2} \mathrm{O}_{3}$ (400 ppm relative to succinic acid) were charged into the round bottom flask of the polycondensation apparatus. The apparatus with the reagents was evacuated several times and filled with nitrogen $\left(\mathrm{N}_{2}\right)$ in order to remove oxygen. During the first reaction step (esterification), reagents were heated at $180^{\circ} \mathrm{C}$ for $4 \mathrm{~h}$ under $500 \mathrm{rpm}$ stirring and $\mathrm{N}_{2}$ flow $(50 \mathrm{~mL} / \mathrm{min}$ ). Water was distilled (as reaction by-product) and was collected in a graduated cylinder. When almost all the theoretical amount of $\mathrm{H}_{2} \mathrm{O}$ was collected (after $3.5 \mathrm{~h}$ ), the first step was considered as completed. Thereafter, in the second step of polycondensation, temperature was gradually increased from 180 to $230{ }^{\circ} \mathrm{C}(15 \mathrm{~min})$ and vacuum was slowly implemented (5.0 Pa) in order to remove unreacted monomers, avoid excessive foaming, and minimize oligomer sublimation. The polycondensation continued for about $15 \mathrm{~min}$, at $230^{\circ} \mathrm{C}$, for all prepared polyesters, while stirring speed was also increased to $750 \mathrm{rpm}$. After that time, polymerization was terminated by rapid cooling to room temperature and the polyesters were removed. It is important to note that in the present study the catalyst $\left(\mathrm{Sb}_{2} \mathrm{O}_{3}\right)$ was not removed from the prepared polyesters, since its concentration was extremely low ( $400 \mathrm{ppm}$ relative to succinic acid), and hence no effect on the physicochemical or thermophysical properties of the prepared polyesters is anticipated. However, before proceeding to an in vivo evaluation (in following studies), a purification method should be adopted in order to remove the catalyst since there are several reports raising serious concerns on its toxicity. The prepared polyesters were stored in hermetically sealed glass vials and placed in desiccators $\left(25^{\circ} \mathrm{C}\right)$ before further use. 


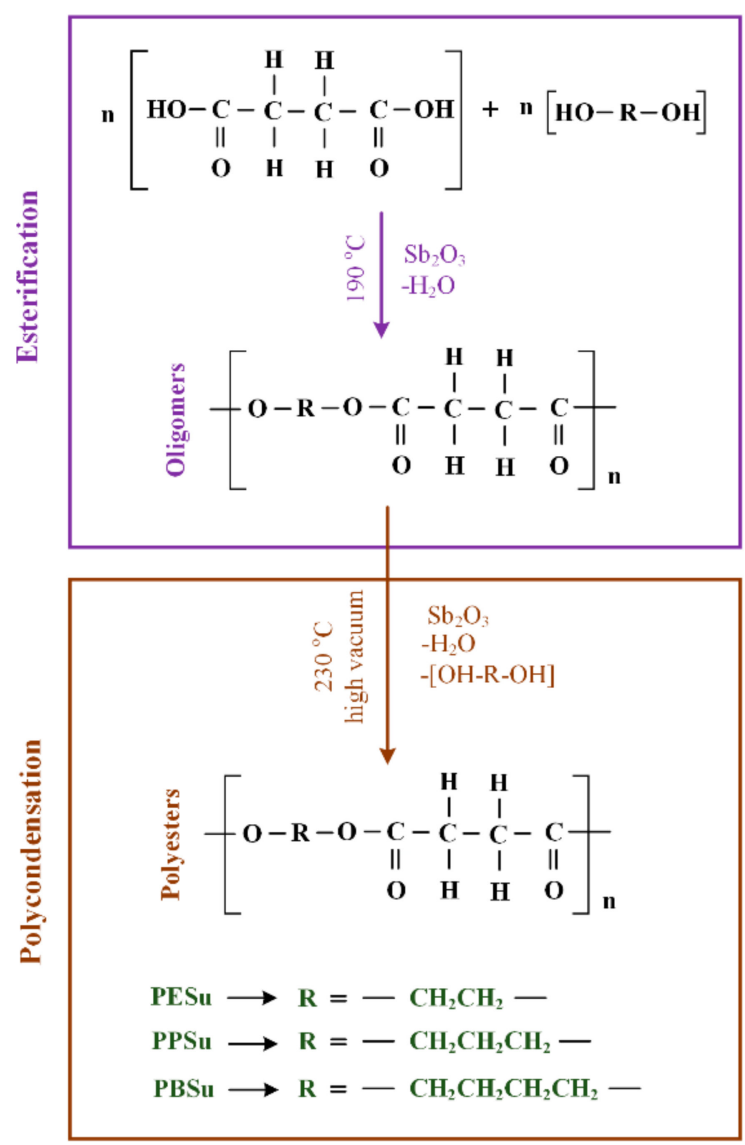

Figure 1. Chemical reaction scheme for the preparation of the poly(alkylene succinate) polyesters via the two-stage melt polycondensation method (esterification-polycondensation).

\subsection{Characterization of Poly(alkylene succinate) Polyesters}

\subsubsection{Intrinsic Viscosity}

The intrinsic viscosity $[\eta]$ measurements of the obtained polyesters were performed by using an Ubbelohde viscometer (Schott Gerate GMBH, Hofheim, Germany). The samples were dissolved in chloroform $\left(\mathrm{CHCl}_{3}\right)$ at room temperature in order to prepare solutions of $1 \% w / v$, and filtered through a disposable membrane filter $0.2 \mu \mathrm{m}$ (Teflon). Intrinsic viscosity was calculated after the Solomon-Ciuta equation [29]:

$$
[\eta]=\frac{\left[2\left\{t / t_{0}-\ln \left(t / t_{0}\right)-1\right\}\right]^{1 / 2}}{c}
$$

where, $c$ is the concentration of the solution, $t$ is the flow time of solution and $t_{\mathrm{o}}$ represents the flow time of pure solvent. The number-average molecular weight $\left(\bar{M}_{n}\right)$ of the samples was calculated from intrinsic viscosity $[\eta]$ values, using the Berkowitz equation:

$$
\bar{M}_{n}=3.29 \times 10^{4}[\eta]^{1.54}
$$

\subsubsection{Size Exclusion Chromatography (SEC)}

SEC was used for the determination of the molecular weight distribution and the average molecular weights of the samples. Molecular weight determinations were performed using a high temperature SEC system by Waters (model 600) equipped with a refractive index detector (Milford, MA, USA) and Water Styragels columns (Milford, MA, USA) in the order of HR1, HR2, HR4, HR4, and HR5. All samples were dissolved in $\mathrm{CHCl}_{3}$ at a constant concentration of $12 \mathrm{mg} / 600 \mu \mathrm{L}$ and filtrated. The elution solvent was $\mathrm{CHCl}_{3}$ at a constant flow rate of $1 \mathrm{~mL} / \mathrm{min}$ and the measurements were performed at $35^{\circ} \mathrm{C}$ and 
$150 \mu \mathrm{L}$ injection volume. Calibration was performed using nine polystyrene standards with narrow molecular weight distribution, 1000-300,000 molecular weight distribution.

\subsubsection{Nuclear Magnetic Resonance Spectroscopy ( $\left.{ }^{1} \mathrm{H}-\mathrm{NMR}\right)$}

${ }^{1} \mathrm{H}-\mathrm{NMR}$ spectra of polyesters $(5 \% w / v)$ were recorded in deuterated chloroform $\left(\mathrm{CDCl}_{3}\right)$, on an Agilent 500 spectrometer (Agilent Technologies, Santa Clara, CA, USA), at room temperature. The number of scans was 16 and the sweep width was $6 \mathrm{kHz}$.

\subsubsection{DSC Measurements}

For the determination of polyesters' thermophysical properties, DSC studies were performed by means of a TA Q200 series DSC instrument (TA, USA). Each sample was scanned using a cyclic scanning procedure. Specifically, the samples were heated from 20 to $190^{\circ} \mathrm{C}$ at a heating rate of $10^{\circ} \mathrm{C} / \mathrm{min}$ and were maintained at that temperature for $3 \mathrm{~min}$ in order to achieve equilibrium and erase any thermal history. Then, the samples were quench cooled at $-100{ }^{\circ} \mathrm{C}$, kept at that temperature for $3 \mathrm{~min}$ and heated again up to $190{ }^{\circ} \mathrm{C}$ with $10{ }^{\circ} \mathrm{C} / \mathrm{min}$. The melting point $\left(\mathrm{T}_{\text {melt }}\right)$ and the crystallization temperature $\left(\mathrm{T}_{\text {cryst }}\right)$ were determined as the onset temperature of the corresponding heat flow peak/event. The $\mathrm{T}_{\mathrm{g}}$ was determined as the inflection point temperature of the heat flow curve, while the enthalpy of fusion $\left(\Delta \mathrm{H}_{\mathrm{f}}\right)$ and crystallization $\left(\Delta \mathrm{H}_{\mathrm{c}}\right)$ were determined as the integrated area of the total heat flow curve.

\subsection{Preparation of PVA-Polyesters Melt Mixtures}

PVA-polyester dispersions were prepared by melt-quenching approach at ratios of $90 / 10,80 / 20$, and $70 / 30 w / w$ of PVA to aliphatic polyester. Briefly, appropriate amounts of PVA were mixed with polyesters in a mortar and pestle, placed in appropriate aluminum pans and then heated at $215{ }^{\circ} \mathrm{C}$ for 5 min until a homogeneous melt dispersion (verified visually and via polarized light microscopy) was obtained. The dispersion was then rapidly cooled in an ice bath, without temperature control, and subsequently pulverized at room temperature with mortar and pestle, and then sieved from a $300 \mu \mathrm{m}$ sieve. All samples were placed in hermetically sealed amber glass vials and stored in a desiccator at room temperature $\left(25^{\circ} \mathrm{C}\right)$ in order to prevent moisture absorption before further analysis.

\subsection{Miscibility Evaluation}

\subsubsection{Theoretical Evaluation}

Hansen solubility parameters (HSP) calculated based on the Hoftyzer-Van Krevelen (HVK) group contribution method, were used in order to theoretically evaluate the miscibility of PVA with the prepared polyesters. Based on this approach, the total solubility parameter $\left(\delta_{t}\right)$ of a molecule describes its ability to interact with other molecules based on the contributions of molar volume $(V)$, dispersion $\left(F_{d}\right)$, polar $\left(F_{p}\right)$ and hydrogen bonding $\left(E_{h}\right)$ forces according to the following equations [30]:

$$
\begin{gathered}
\delta_{t}=\sqrt{\delta_{d}^{2}+\delta_{p}^{2}+\delta_{h}^{2}} \\
\delta_{d}=\frac{\sum_{i} F_{d i}}{\sum_{i} V_{i}}, \delta_{p}=\frac{\sqrt{\sum_{i} F_{p i}^{2}}}{\sum_{i} V_{i}}, \delta_{h}=\frac{\sqrt{\sum_{i} E_{h}}}{\sqrt{\sum_{i} V_{i}}}
\end{gathered}
$$

where, $\delta_{d}, \delta_{p}$, and $\delta_{h}$ are the partial solubility parameters for intermolecular dispersion, polar, and hydrogen bonding forces, respectively.

In addition to HSP, the miscibility of compounds was also evaluated theoretically via MD simulations. Using this approach, the miscibility of compounds is evaluated in the melt, instead of $25^{\circ} \mathrm{C}$, which is crucial in melt-based pharmaceutical processes. Details on the methodology followed for MD simulations are given in Section 2.9. 


\subsubsection{Experimental Evaluation}

Hot stage polarized light microscopy (HSM) was used for the experimental verification of a component's miscibility during melting. Specifically, physical mixtures of PVA and polyesters (at ratio of 90/10, 80/20, and 70/30 $w / w$ PVA to polyester) were heated from $25{ }^{\circ} \mathrm{C}$ until complete PVA melting $\left(210{ }^{\circ} \mathrm{C}\right)$, using a rate of $10^{\circ} \mathrm{C} / \mathrm{min}$ on a Linkam THMS600 heating stage (Linkam Scientific Instruments Ltd., Surrey, UK), mounted on Olympus BX41 polarized light microscope, and controlled through a Linkam TP94 temperature controller. Evaluation of miscibility was made by visual observation.

\subsection{Thermal Properties Evaluation}

DSC pans containing accurately weighted amounts $(\sim 5.0 \mathrm{mg})$ of samples (PVApolyesters mixtures) were melt-quenched by heating up to $230{ }^{\circ} \mathrm{C}$ with a heating rate of $10{ }^{\circ} \mathrm{C} / \mathrm{min}$, keeping it isothermal for $3 \mathrm{~min}$, in order to erase any thermal history, cooling at a rate of $10{ }^{\circ} \mathrm{C} / \mathrm{min}$ to $20^{\circ} \mathrm{C}$, before re-heating again at the same rate up to approx. $10^{\circ} \mathrm{C}$ above PVA's melting point. The instrument was calibrated for temperature using benzophenone, indium, and tin. The enthalpic response was calibrated using high purity indium. The melting point temperature $\left(\mathrm{T}_{\mathrm{m}}\right)$ was determined as the onset temperature of the heat flow curve, the glass transition temperature $\left(\mathrm{T}_{\mathrm{g}}\right)$ was determined as the inflection point temperature of the heat flow curve, while the enthalpy of fusion $\left(\Delta \mathrm{H}_{\mathrm{f}}\right)$ was determined as the integrated area of the total heat flow curve. The standard deviations of temperatures and enthalpies determined in this work were not higher than $1.0^{\circ} \mathrm{C}$ and $3.0 \mathrm{~J} / \mathrm{g}$, respectively. All experiments were conducted in triplicate.

Thermo-gravimetric analysis (TGA) was performed in a Shimadzu TGA-50 thermogravimetric analyzer (Tokyo, Japan). Approximately, $5.0 \mathrm{mg}$ of samples (pure components and PVA-polyesters mixtures at 90/10, 80/20, 70/30 \% w/w PVA to polyester ratio) were placed into an aluminum sample pan, which was attached to a sensitive microbalance assembly, and heated from 25 to $300^{\circ} \mathrm{C}$ at a rate of $10^{\circ} \mathrm{C} / \mathrm{min}$, using nitrogen as purge gas at a flow rate of $25 \mathrm{~mL} / \mathrm{min}$. All experiments were performed in triplicate.

\subsection{Physical State Evaluation}

Powder X-ray diffracrometry (pXRD) patterns of the pure components (PVA and polyesters) and the PVA-polyesters melt mixes (prepared according to Section 2.4) were recorded using an $\mathrm{X}$-ray diffractometer (Rigaku-Miniflex II) with a CuK $\alpha$ radiation source for crystalline phase identification $(\lambda=0.15405 \mathrm{~nm}$ for $\mathrm{CuK} \alpha)$. All samples were scanned from 5 to $50^{\circ} 2<$ theta $>$, at steps of $0.05^{\circ}$.

\subsection{Molecular Interactions Evaluation}

\subsubsection{Experimental Evaluation}

Molecular interactions between PVA and the tested polyesters were experimentally studied via attenuated total reflectance FTIR spectroscopy (ATR-FTIR). Specifically, the ATR-FTIR spectra of pure components, physical mixtures, and melt mixtures were obtained in the region of 750-4000 $\mathrm{cm}^{-1}$ using a Shimadzu IR-Prestige-21 FT-IR spectrometer (Tokyo, Japan), coupled with a horizontal Golden Gate MKII single-reflection ATR system (Specac, Kent, UK) equipped with ZnSe lenses after appropriate background subtraction. Sixty-four (64) scans over the selected wavenumber range at a resolution of $4 \mathrm{~cm}^{-1}$ were averaged for each sample.

\subsubsection{Theoretical Evaluation}

In order to gain an in-depth understanding of the molecular interactions evolving between PVA and the studied polyesters, MD simulations were conducted (details on the methodology followed are given in the following section). 


\subsection{Molecular Dynamics (MD) Simulations}

\subsubsection{Preparation of Initial Structures}

The initial structure of PVA (50 monomers) having a 90\% degree of hydrolysis (five hydroxyl units were replaced with acetyl units) was prepared based on a previous study of ours [24]. The initial structures of PPSu, PESu and PBSu (having five monomers each) were constructed using VEGAZZ v.3.1.2.39 [31]. All molecular structures were then optimized via energy minimization simulations runs using the pcff_d force field [32] with XenoView v.3.7.9.0 suite [33]. During geometry optimization, tolerance was set at $1.00 \mathrm{E}-4 \mathrm{kcal} / \mathrm{mol}$, while maximum displacement per iteration was set at $10 \AA$. A total of ten structures (for each component) were optimized and those with the lowest energy were selected for further analysis.

\subsubsection{Contraction of Amorphous Cells}

In order to build the amorphous cells, Xenoview's amorphous builder was used by varying the rotatable torsions via the free rotation model method. A total of ten independent simulation boxes were constructed having twenty PPSu, PESu and PBSu chains and minimized steepest descent algorithm with $1.00 \times 10^{-4} \mathrm{kcal} / \mathrm{mol}$ tolerance and a $10 \AA$ maximum displacement per iteration in order to remove unfavorable interactions and attain the lowest energy state. The amorphous cell of PVA was obtained from a previous study of ours [24]. The structure with the lowest energy was selected for further processing. The cell structure having the lowest energy in each case was further equilibrated following a multistep equilibration protocol proposed by Li et al. [34], during which the torsion angles have sufficient time to relax into new distributions under the effect of full non-bonded interactions. In this way, the chain conformation differences within the initial chain growth step are being eliminated.

\subsubsection{Simulation Runs}

A two-phase MD simulations protocol was adopted. Initially, an equilibration phase was employed in order to relax the obtained structures for $2.0 \mathrm{~ns}$ under the NVT ensemble at $200{ }^{\circ} \mathrm{C}$ (approximately the melting temperature of PVA) with pcff_d force field, $1.0 \mathrm{fs}$ time step and Berendsen thermostat. Then in the production phase the structures obtained were subjected in a further $1.0 \mathrm{~ns}$ processing under NPT (variable volume and shape) at atmospheric pressure $(1 \mathrm{~atm})$ and $200{ }^{\circ} \mathrm{C}$, using a cut-off radius of $10.0 \AA$, spline distance of $1 \AA$, Berendsen thermost, Berendsen barostat, and $1.0 \mathrm{fs}$ time step. In all cases, the validity of the simulations was ensured by following the criteria suggested by van Gunsteren and Mark [35].

Determination of compound's miscibility: In order to evaluate the miscibility of components, the assemblies obtained from the previous MD runs were subjected in a further 200 ps processing under NPT with the same MD parameters. The final 50 ps of the trajectory were used for computing the cohesive energy $\left(E_{c o h}\right)$ and the solubility parameter $(\delta)$ according to the following equation:

$$
\delta=\sqrt{\frac{E_{c o h}}{V}}
$$

where, $V$ is the volume estimated by MD simulations.

Interaction energy $\left(E_{\text {inter }}\right)$ : $E_{\text {inter }}$ is a characteristic parameter which can represent the interaction force of components in composite system. The interaction energy can be evaluated by the total energy of the blends and each component in the system according to the following equation [36]:

$$
\mathrm{E}_{\text {inter }}=\mathrm{E}_{\mathrm{tot}}(P V A / \text { polyester })-\mathrm{E}_{\mathrm{tot}}(P V A)-\mathrm{E}_{\mathrm{tot}}(\text { polyester })
$$


where, $\mathrm{E}_{\text {tot }}(P V A /$ plasticizer $)$ is the energy of the polymer/polyester system, $\mathrm{E}_{\text {tot }}(P V A)$ is the energy of pure PVA and $\mathrm{E}_{\text {tot }}$ (polyester) is the energy of the pure poly(alkylene succinate) polyesters.

Molecular interactions: The radial distribution function, RDF or $\mathrm{g}(\mathrm{r})$, was calculated for PVA's hydroxyl hydrogens around the poly(alkylene succinate) polyesters's oxygens at $200{ }^{\circ} \mathrm{C}$ in order to gain an insight into the molecular interactions evolving between the compounds during the melting process.

\subsection{Melt Flow Index (MFI)}

The MFIs of pure PVA and PVA- poly(alkylene succinate) polyester melts (at a ratio of $30 \% w / w$ polyester to PVA) were measured at temperatures $190,200,210$, and $220^{\circ} \mathrm{C}$, using CEAST's Melt Flow Quick Index meter (CEAST, Turin, Italy) according to the ASTM standard D 1238-04 and ISO standard 1133 (load $2.16 \mathrm{~kg}$ ).

\section{Results and Discussion}

\subsection{Characterization of Poly(alkylene succinate) Polyesters}

The proposed two-stage polycondensation method resulted in the formation of poly(alkylene succinate) polyester having an almost white (PESu and PBSu) to light-brown (PPSu) color. All prepared materials were soft (waxy-like) with PESu being more brittle and PPSu being more elastic than the others.

\subsubsection{H NMR Results}

The obtained ${ }^{1} \mathrm{H}$ NMR spectra for the three polyesters are presented in Figure 2. The ${ }^{1} \mathrm{H}$ NMR spectrum of PESu showed only two characteristic peaks at 2.55-2.67 and 4.18-4.3 ppm attributed to methylene protons of succinic acid, a, and of ethylene glycol, $\mathrm{b}$, respectively. In the case of PPSu, there was a single peak at $2.63 \mathrm{ppm}$ attributed to methylene protons of succinic acid, a, a triple peak at 4.09-4.21 ppm attributed to c protons and a multiple peak between 1.9 and 2.02 ppm corresponding to $\mathrm{d}$ protons. $\mathrm{PBSu}{ }^{1} \mathrm{H}$ NMR spectrum presented a triple peak at 4-4.2 ppm attributed to e proton groups and a multiple peak at $1.8-2 \mathrm{ppm}$ attributed to $\mathrm{f}$ proton groups. The above- mentioned results were in agreement with previous studies [37-39], indicating that the selected two-stage melt polycondensation method (i.e., esterification and polycondensation) was able to prepare the desired poly(alkylene succinate) polyesters (i.e., PESu, PPSU, and PBSu).

\subsubsection{Intrinsic Viscosity-Molecular Weight}

Table 1 summarizes the intrinsic viscosity and SEC results for the three prepared polyesters. PPSu showed the lowest intrinsic viscosity (with a value of $0.07 \mathrm{dL} / \mathrm{g}$ ) which was significantly lower compared to the rest polyesters $(0.13$ and $0.16 \mathrm{dL} / \mathrm{g}$ for PESu and PBSu, respectively). Gel permeation chromatography measurements showed that all polyesters had relatively low average molecular weights $(\mathrm{Mw})$ with values ranging from $3056 \mathrm{~g} / \mathrm{mol}$ for PESu to 6551 and $8833 \mathrm{~g} / \mathrm{mol}$ for PPSu and PBSu, respectively. Polydispersity (i.e., $\mathrm{Mw} / \mathrm{Mn}$ ) ranged from 2.08 to 2.56 which is typical for such polyesters [37]. 


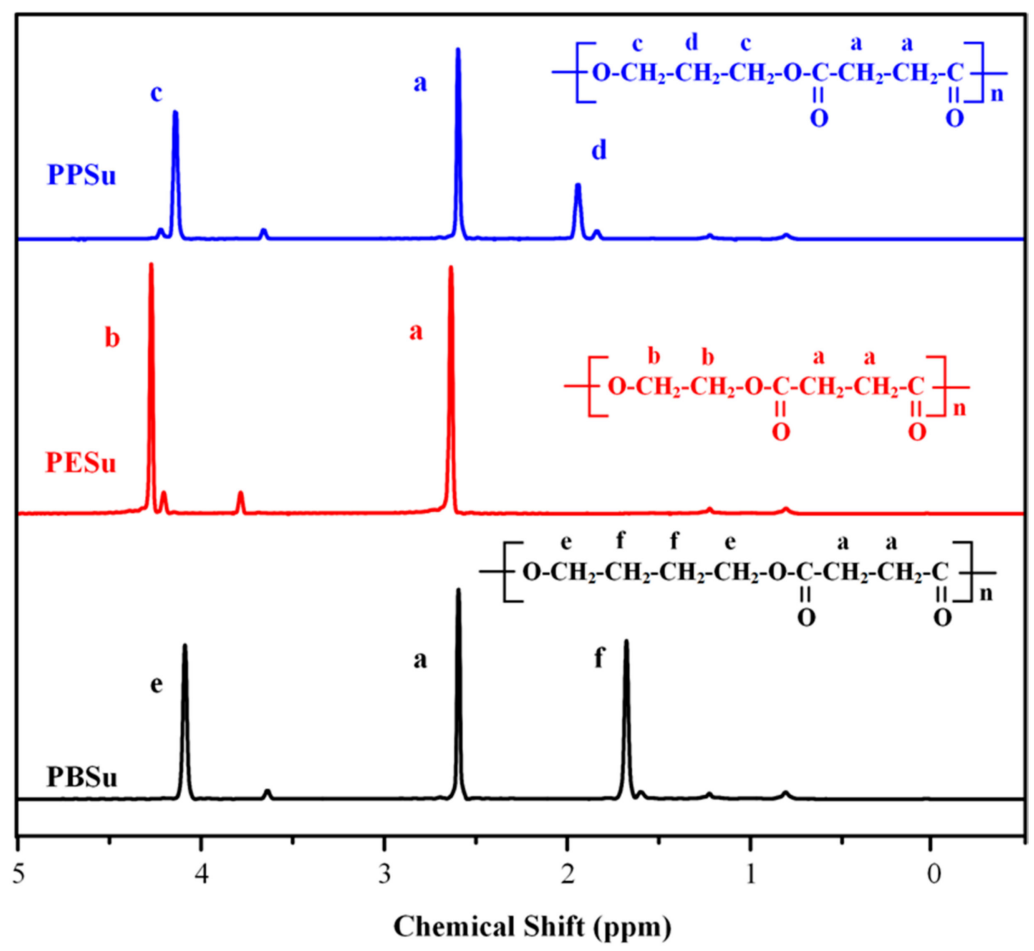

Figure 2. ${ }^{1} \mathrm{H}-\mathrm{NMR}$ spectra of the prepared poly(alkylene succinate) polyesters (PPSu, PESu and PBSu).

Table 1. Intrinsic viscosity, molecular weights and thermal properties of the prepared poly(alkylene succinate) polyesters (PESu, PPSu and PBSu).

\begin{tabular}{cccccccccc}
\hline Polyester & $[\mathbf{\eta}] \mathbf{( d L / g})$ & $\begin{array}{c}\mathbf{M n} \\
(\mathbf{g} / \mathbf{m o l})\end{array}$ & $\begin{array}{c}\mathbf{M w} \\
(\mathbf{g} / \mathbf{m o l})\end{array}$ & $\mathbf{M w} / \mathbf{M n}$ & $\mathbf{T}_{\mathbf{m}}\left({ }^{\mathbf{o}} \mathbf{C}\right)$ & $\mathbf{T}_{\mathbf{g}}\left({ }^{\mathbf{o}} \mathbf{C}\right)$ & $\mathbf{T}_{\mathbf{c}}\left({ }^{\mathbf{o}} \mathbf{C}\right)$ & $\Delta \mathbf{H}(\mathbf{J} / \mathbf{g})$ & $\mathbf{C F}_{\mathbf{c}}(\mathbf{\%})$ \\
\hline PESu & 0.13 & 1196 & 3056 & 2.56 & 93 & -24 & 27 & 68 & 40 \\
PPSu & 0.07 & 2823 & 6551 & 2.36 & 45 & -40 & - & - & - \\
PBSu & 0.16 & 4238 & 8833 & 2.08 & 111 & -41 & 77 & 85 & 5 \\
\hline
\end{tabular}

\subsubsection{Thermal Properties}

Since the aim of the present study was to evaluate the plasticizing ability of poly(alkylene succinate) polyesters in melt-based pharmaceutical applications (such as ASDs utilizing PVA as a suitable matrix carrier), polyesters' thermal properties were analyzed via DSC. Figure 3a presents the 1st heating DSC scan thermograms for the pure polyesters, while Table 1 summarizes the observed thermal events. Results showed that PPSu exhibits a significantly lower melting temperature $\left(\mathrm{T}_{\mathrm{m}}=45^{\circ} \mathrm{C}\right)$ compared to PBSu and PESu $\left(\mathrm{T}_{\mathrm{m}}\right.$ at 111 and $93{ }^{\circ} \mathrm{C}$, respectively), while all polyesters showed a small recrystallization exotherm prior to melting, indicating that the prepared components were semi-crystalline in nature. After melting, all polyesters were subjected to rapid quench cooling in order to obtain completely amorphous samples. Figure $3 \mathrm{~b}$ shows the DSC heating thermograms of the samples after melt-quench cooling. According to the obtained results, PPSu and PBSu presented similar $\mathrm{T}_{\mathrm{g}}$ values (at $-40{ }^{\circ} \mathrm{C}$ and $-41^{\circ} \mathrm{C}$, respectively), while PESu showed a slightly higher $\mathrm{T}_{\mathrm{g}}\left(\right.$ at $\left.-24{ }^{\circ} \mathrm{C}\right)$. In addition, results showed that PPSu was the only polyester that remained completely amorphous (at least within the experimental time scale for scans at $10{ }^{\circ} \mathrm{C} / \mathrm{min}$ ). This is extremely important when the use of plasticizer is intended for pharmaceutical applications targeting the complete drug amorphization (such as hot-melt extrusion), since the crystallinity of the matrix compounds (i.e., the polymer and plasticizer) may act as a substrate for drug's recrystallization. Finally, the crystalline 
fraction $\left(\mathrm{CF}_{\mathrm{c}}\right)$ for the rest polyesters (Table 1$)$, calculated based on the heat of fusion for pure crystalline materials (i.e., $180 \mathrm{~J} / \mathrm{g}$ for PESu, and $210 \mathrm{~J} / \mathrm{g}$ for PBSu) [26], showed significantly less recrystallization for PESu compared to PBSu (5 compared to $30 \mathrm{wt} \%$, respectively), indicating that PESu is less susceptible to recrystallization compared to PBSu.
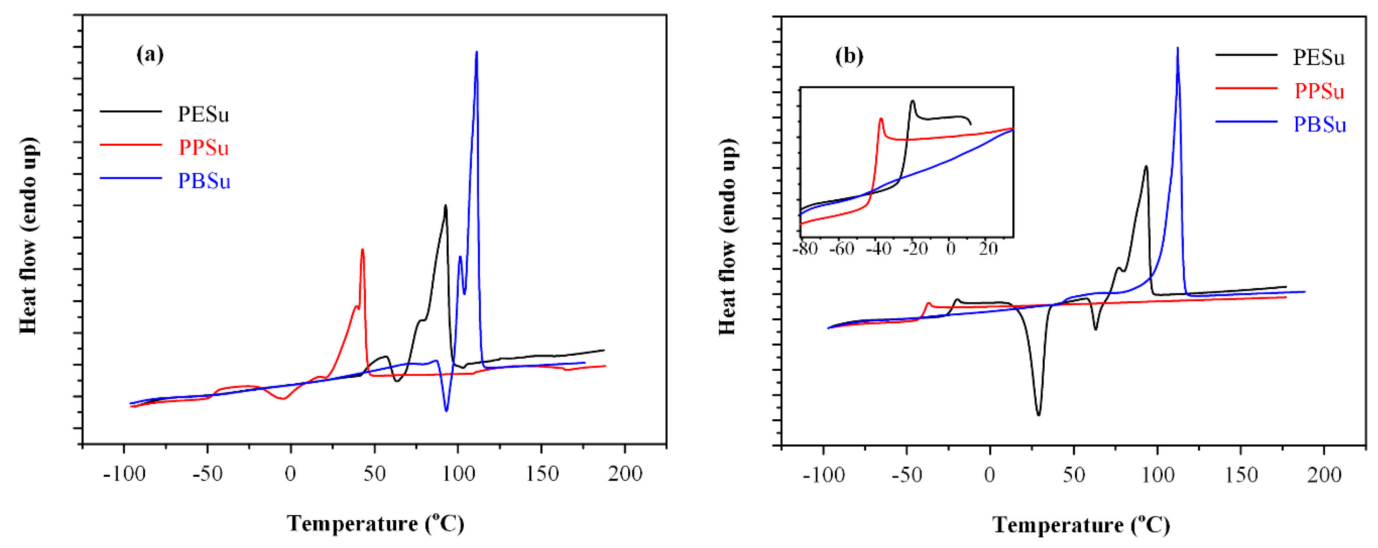

Figure 3. DSC thermograms of polyesters (a) as received from glass reactor and (b) after quenching cooling.

\subsection{PVA- Poly(alkylene succinate) Polyesters Characterization \\ 3.2.1. Miscibility Evaluation}

In general, plasticizers reduce the melting temperature and glass transition temperatures $\left(\mathrm{T}_{\mathrm{g}}\right)$ of polymers (such as PVA) via a process called plasticization (described by the free volume theory). However, in order for this to happen, the two components (i.e., the polymer and the plasticizer) must be completely miscible with each other. In addition, components' miscibility (referring to the ability of producing a homogeneous single phase where the components are mixed at a molecular level) significantly affects the physical stability of the drug-polymer-plasticizer system [40]. An immiscible polymer-plasticizer system could lead to unexpected destabilization, which in turn results to a higher tendency for the API to recrystallize (i.e., change in its physical state) and subsequently to a change in its bioavailability profile $[41,42]$.

\section{Theoretical Evaluation}

HSP method: Initially, the miscibility of PVA with the three prepared polyesters was evaluated based on the difference of the HSPs $\left(\Delta \delta_{t}\right)$ of components estimated via the HVK group contribution method. This approach is based on Greenhalgh et al. suggestion that components are immiscible when $\Delta \delta_{t}>10 \mathrm{MPa}^{1 / 2}$, miscible when $\Delta \delta_{\mathrm{t}}<7 \mathrm{MPa}^{1 / 2}$ and likely to form a glassy solid solution when $\Delta \delta_{t}<2 \mathrm{MPa}^{1 / 2}$ [43]. Additionally, systems with a difference of 7.4 to $15 \mathrm{MPa}^{1 / 2}$ are considered slightly immiscible in the liquid state, while total immiscibility is observed in systems with differences greater than $15 \mathrm{MPa}^{1 / 2}$ [44]. Based on the above, the HSP, along with the $\Delta \delta_{\mathrm{t}}$ (in absolute values) for all systems are summarized in Table 2. Results showed that, at least according to the HSPs, the studied polyesters are slightly immiscible with PVA in the liquid state, since the absolute difference in HSP values were between 7.4 and $15.0 \mathrm{MPA}^{1 / 2}$ (namely 12.4, 12.1 and $11.9 \mathrm{MPA}^{1 / 2}$ for PESu, PPSu and PBSu, respectively). However, although widely employed, the evaluation of miscibility via HSPs via the HVK method presents several limitations, including the fact that the estimations do not account for the effect of temperature or the molecular interactions evolving between the systems' components, such as hydrogen-bonds [44]. 
Table 2. HSPs, MD-based solubility parameters $\left(\delta_{M D}\right)$ and the absolute difference between the corresponding values $\left(\Delta \delta_{t}\right)$ for PVA and the prepared poly(alkylene succinate) polyesters (PESu, PPSu and PBSu).

\begin{tabular}{ccccc}
\hline & \multicolumn{4}{c}{ Substances } \\
\cline { 2 - 5 } & PVA & PESu & PPSu & PBSu \\
\hline HVK group contribution method & & & \\
HSPs $\left(\mathrm{MPa}^{1 / 2}\right)$ & 34.0 & 21.6 & 21.9 & 22.1 \\
$\Delta \delta_{\mathrm{t}}\left(\mathrm{MP}^{1 / 2}\right)$ & - & 12.4 & 12.1 & 11.9 \\
$\mathrm{MD} \mathrm{simulations}$ & & & & \\
$\delta_{\mathrm{MD}}\left(\mathrm{MPa}^{1 / 2}\right)$ & 26.1 & 26.8 & 25.5 & 24.4 \\
$\Delta \delta_{\mathrm{t}}\left(\mathrm{MP}^{1 / 2}\right)$ & - & 0.7 & 0.6 & 1.7 \\
\hline
\end{tabular}

MD simulations: In order to overcome some of the limitations associated with the HSP calculations based on the group contribution method, the miscibility of components was also evaluated theoretically via MD simulations. In this approach, the solubility parameters of components $\left(\delta_{M D}\right)$ were estimated at $200{ }^{\circ} \mathrm{C}$ based on Equation (5). Figure 4 shows the MD-simulation boxes containing the 20 polyester chains used to evaluate the solubility parameter $\delta_{M D}$. In the case of PVA, the results were obtained from a previous study of ours [24]. The MD-based solubility parameters along with the $\Delta \delta_{\mathrm{t}}$ results are presented in Table 2. Results showed that in all cases, at least based on MD simulations, the prepared poly(alkylene succinate) polyesters may be considered as completely miscible with PVA, since all estimated $\delta_{M D}$ differences were below 2.0. This result is not in agreement with the previous suggestions made by HSPs analysis, where the two components were identified as being slightly immiscible. The differences observed between the two approaches (i.e., the MD simulations and the group contribution method) are probably due the fact that the group contribution method depends on constant group values that do not account for the thermodynamic and kinetic state of the compounds as well as the fact that the latter case does not account for the effect of the temperature [45].

\section{Experimental Evaluation}

The most frequently used experimental technique to prove components' miscibility is by far the identification of a single $\mathrm{T}_{\mathrm{g}}$ using DSC $[42,46]$. However, according to recent studies, the evaluation of miscibility via DSC is related to several drawbacks and limitations, leading to inadequate results $[46,47]$. Among the several other alternative techniques suggested (such as pXRD and solid-state NMR) HSM may be considered as the easiest to implement. With HSM, miscibility in the melt state can be easily detected, since miscible compounds form a uniform melt region, while the interfacial tensions in immiscible compounds cause each melt to maintain their surface as small as possible, forming thus an 'oil-water' like immiscible melt region [24]. Figure 5 presents the HSM obtained images at the melting point of the pure PVA and the PVA-polyesters systems. Based on the obtained results, PVA and the examined polyesters were completely miscible at the melt state, since no de-mixing zones were observed between the components. This result indicates that the use of MD-simulations is more suitable to predict the melt miscibility of components compared to the HSP approach using the group contribution method. 


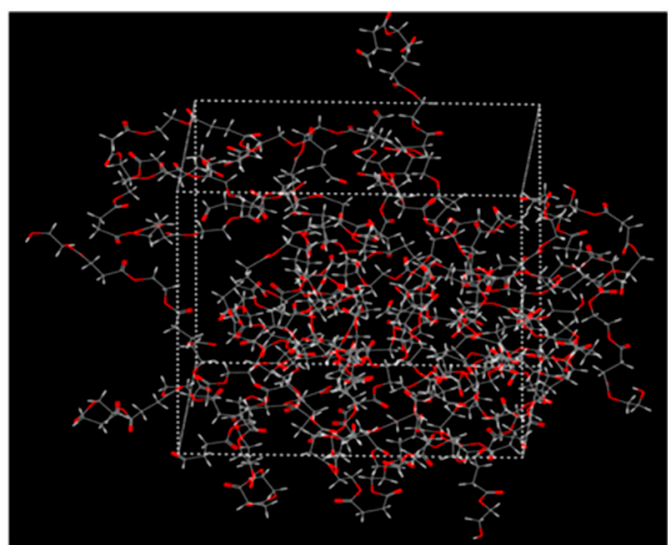

PESu

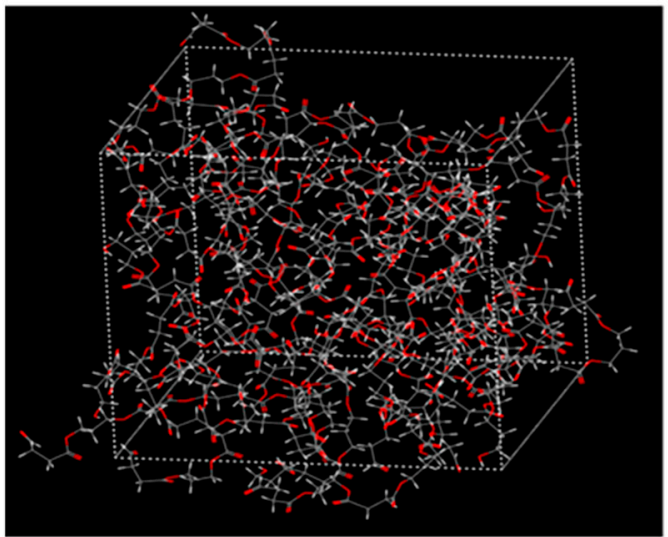

PPSu

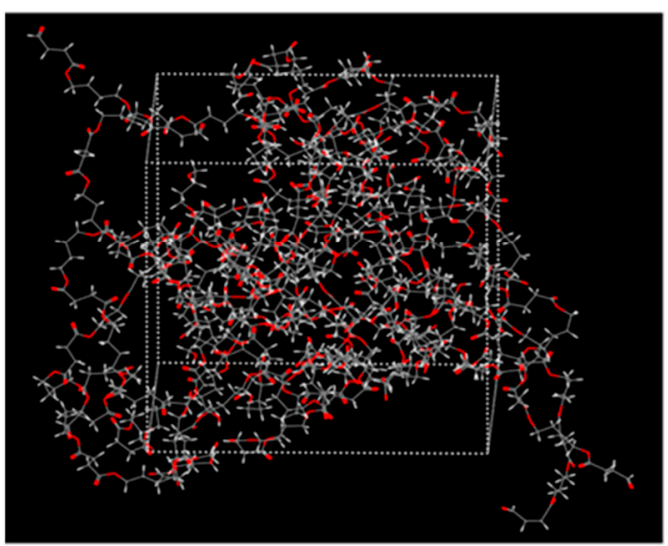

PBSu

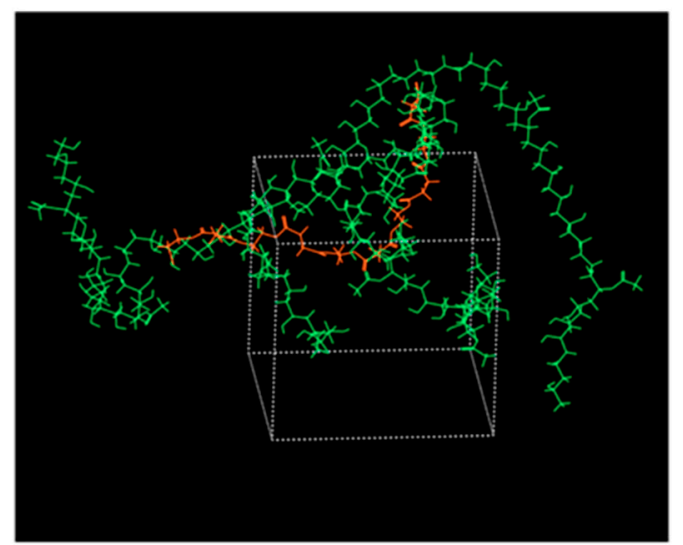

PVA-PESu

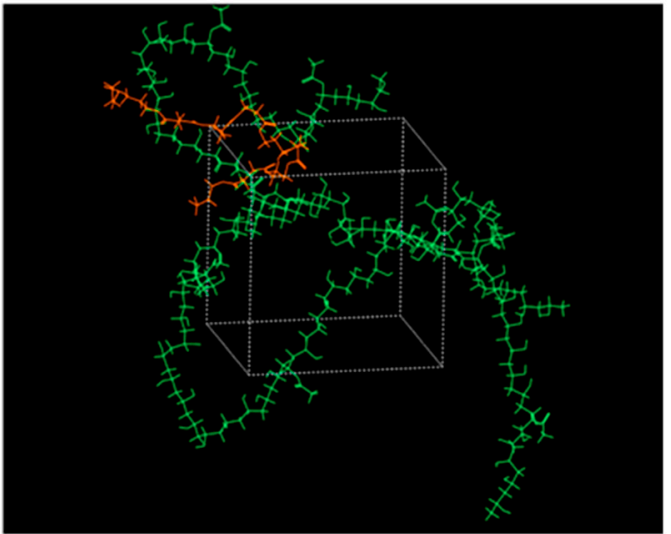

PVA-PPSu

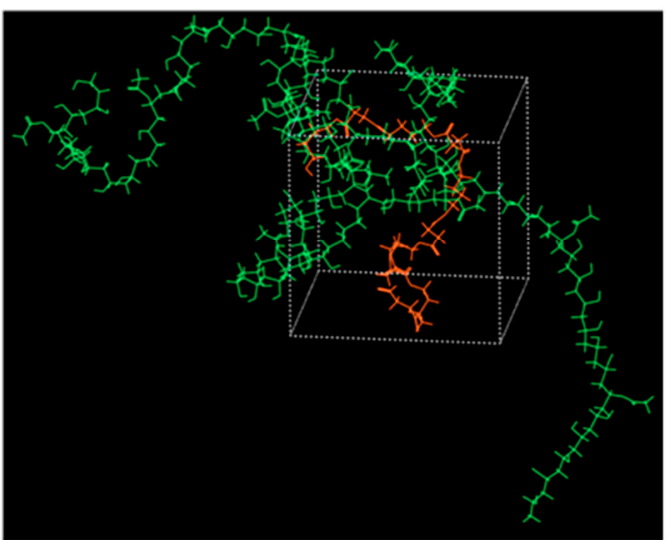

PVA-PBSu

Figure 4. MD-simulation boxes containing twenty polyester chains (hydrogen atoms with white, carbon atoms with grey and oxygen atoms with red) or the mixtures of the polyesters (orange) with PVA (green). 


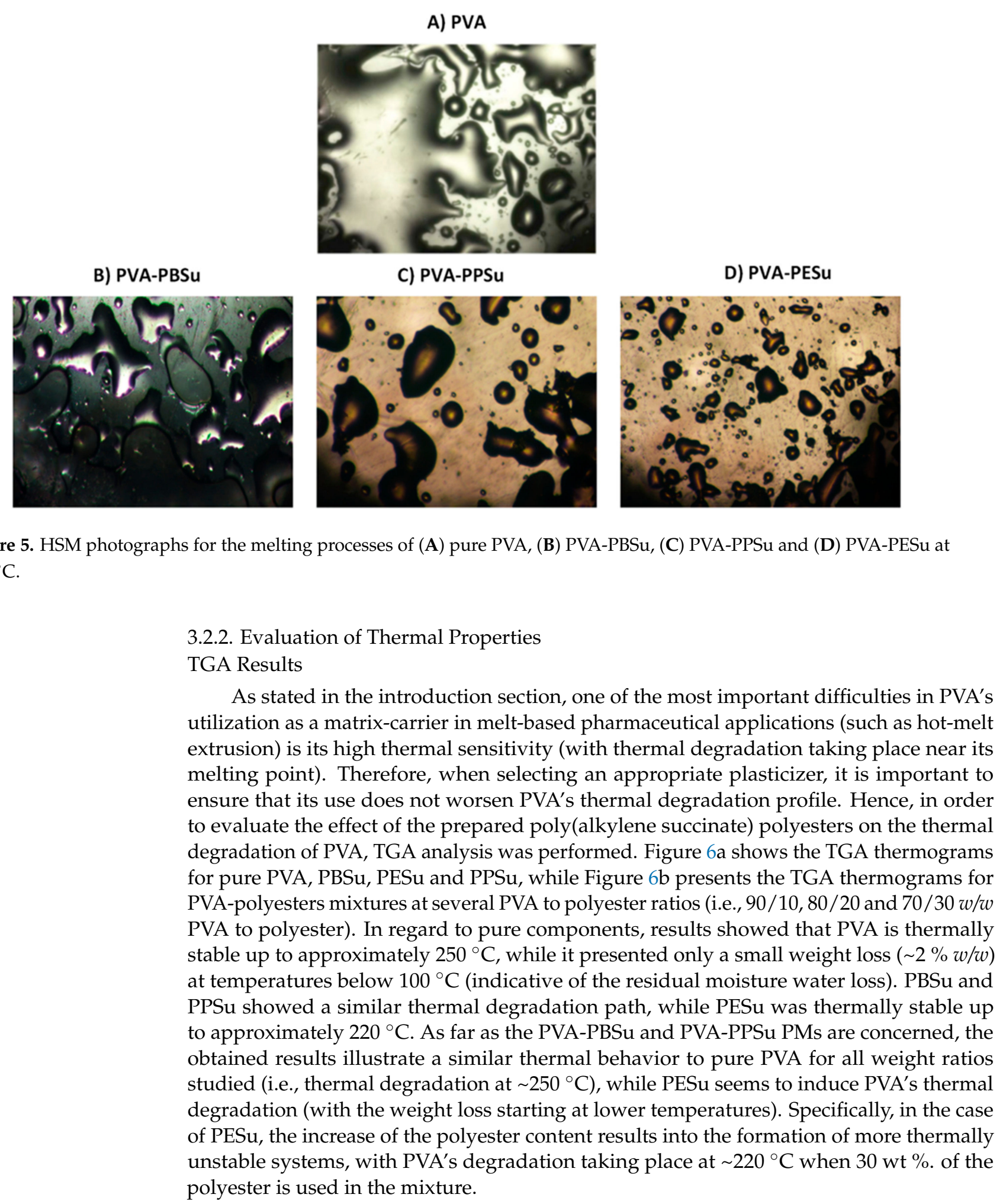


(a)

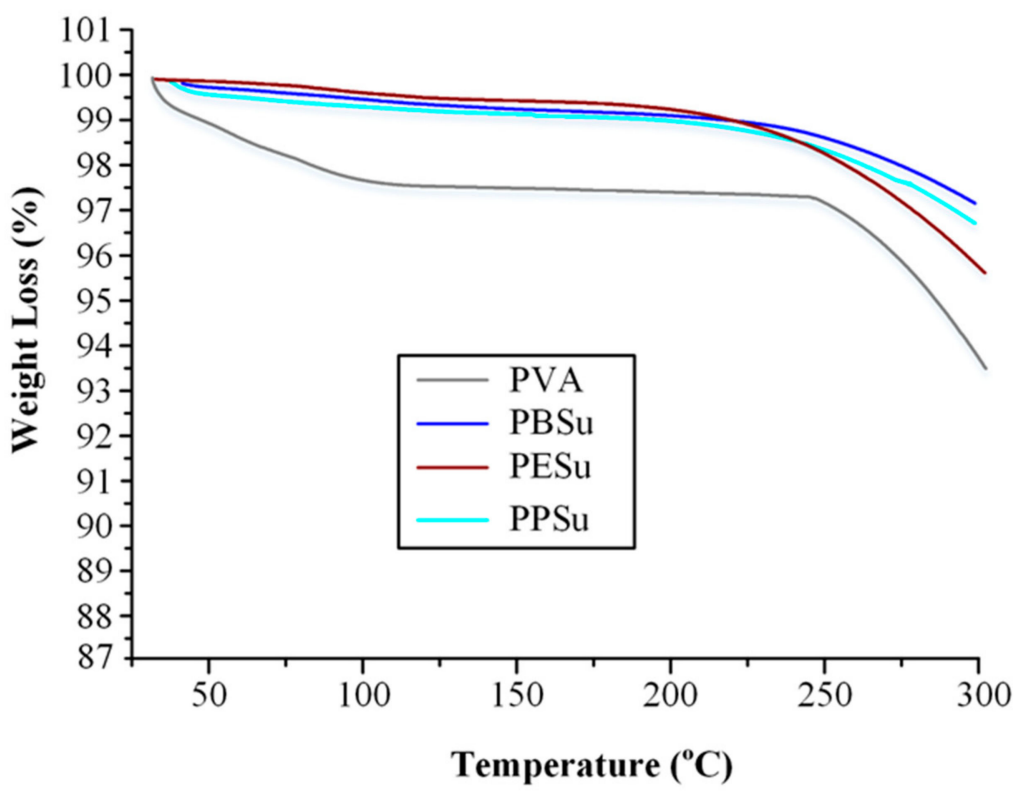

(b)

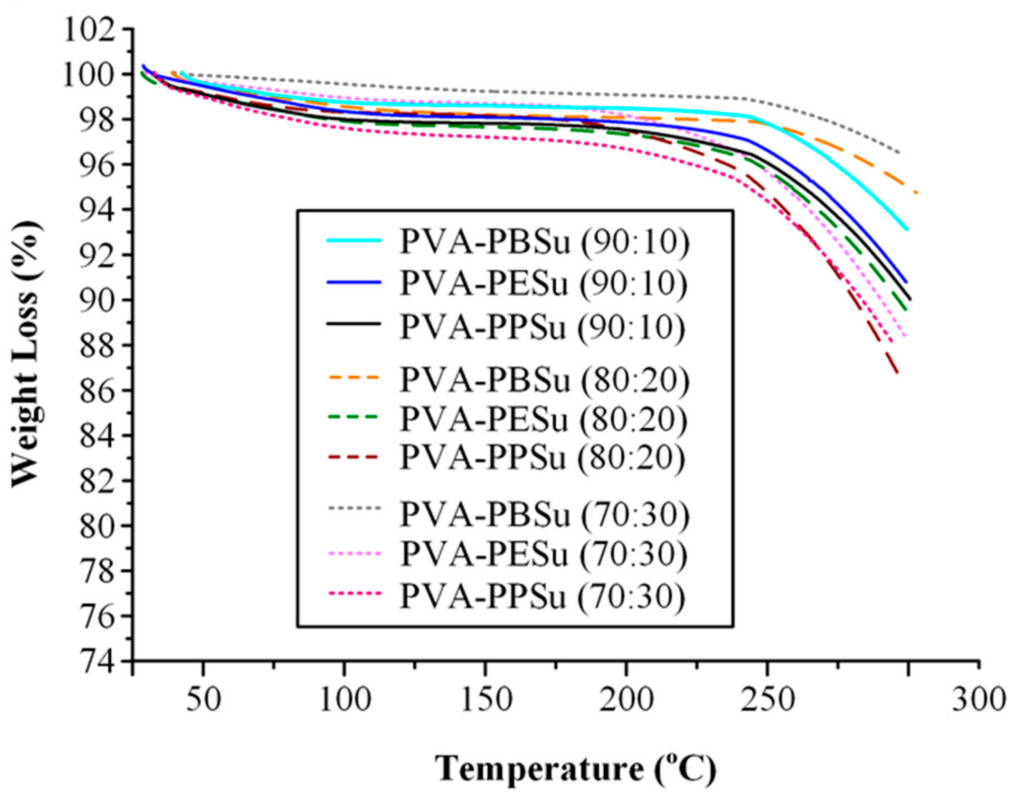

Figure 6. TGA thermograms of (a) neat PVA, PBSu, PESu and PPSu and (b) PVA-polyester mixtures at several weight ratios.

DSC Results

In addition to thermal stability, the plasticizing effect of polyesters (i.e., the reduction on PVA's $T_{g}$ and $T_{m}$ ) was evaluated via DSC. Figure 7a shows the DSC thermograms from the first heating scan of the pure components and the PVA-plasticizer mixtures. In the case of pure PVA, the obtained DSC thermogram showed a single melting endotherm starting at $171.8^{\circ} \mathrm{C}$ with $\Delta \mathrm{H}_{\mathrm{f}}$ of $41.69 \mathrm{~J} / \mathrm{g}$. In the case of PVA-PPSu mixtures results showed that as the polyester content increases (i.e., from 10 to $30 \mathrm{wt} \%$ ) PVA's melting temperature significantly reduces (i.e., from $166^{\circ} \mathrm{C}$ to $157^{\circ} \mathrm{C}$, respectively). Similarly, although not so pronounced, the other two poly(alkylene succinate) polyesters also showed a significant reduction in PVA's melting temperature (30 wt \% addition of PESu or PBSu reduced PVA's melting temperature to $163^{\circ} \mathrm{C}$ or $165^{\circ} \mathrm{C}$, respectively). 
(a)
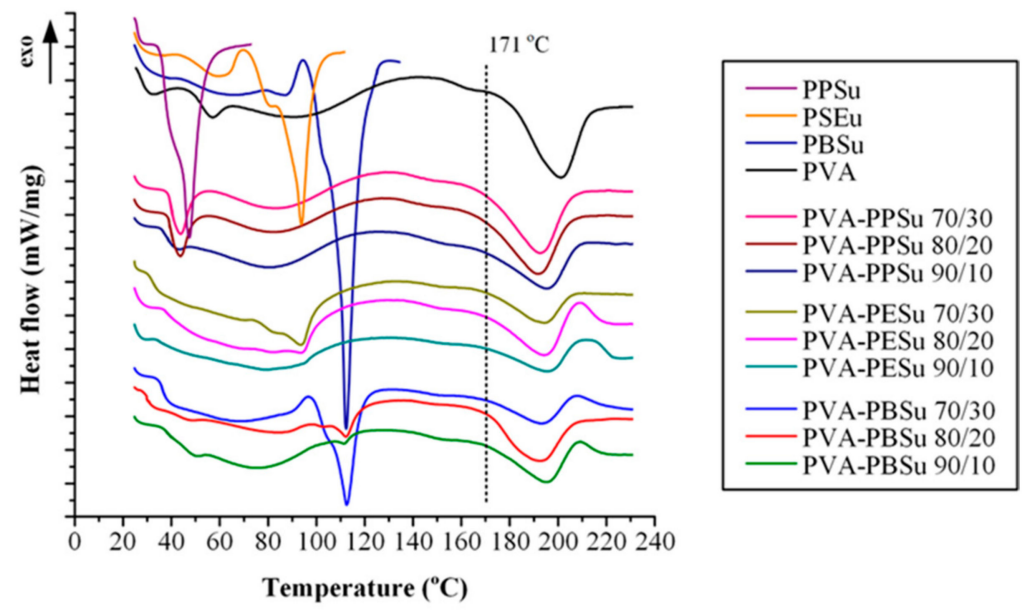

(b)
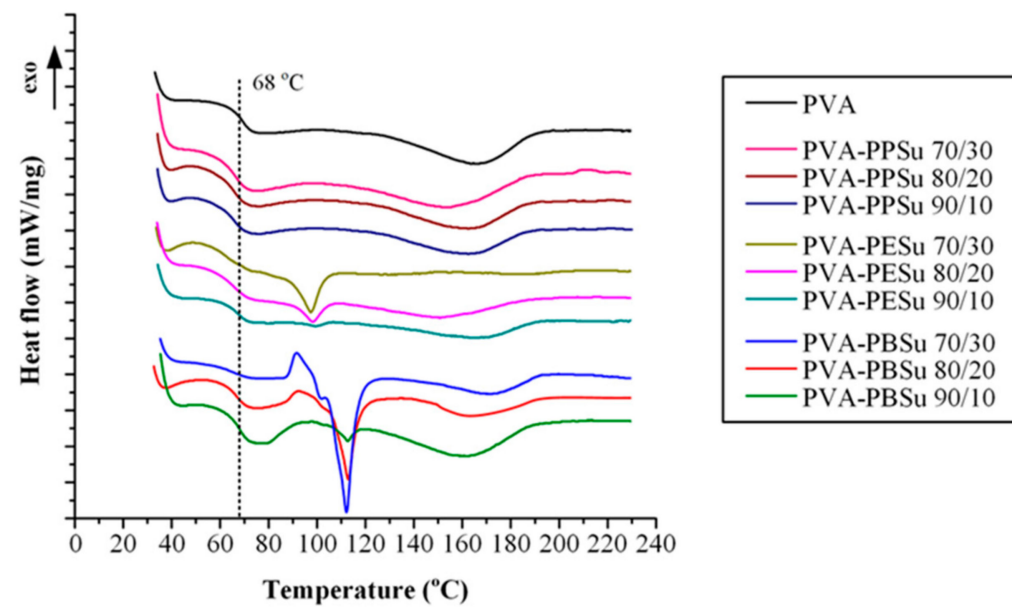

Figure 7. DSC thermograms of the PVA, polyesters and the PVA-polyesters mixtures during (a) the 1st and (b) the 2nd heating scans.

Figure $7 \mathrm{~b}$ shows the DSC thermograms obtained after the melt-quench cooling procedure (i.e., 2 nd heating scan). In the case of pure PVA, a single $\mathrm{T}_{\mathrm{g}}$ was initially recorded at $68{ }^{\circ} \mathrm{C}$, while a broad endothermic peak was also observed at $\sim 170{ }^{\circ} \mathrm{C}$ corresponding to PVA's melting, with the $\Delta \mathrm{H}_{\mathrm{f}}$ of $15.3 \mathrm{~J} / \mathrm{g}$ indicating that the crystalline part of PVA was significantly reduced after the followed quench cooling procedure. In the case of PVA-polyester mixtures, results showed that except for PPSu (which was amorphous) the rest poly(alkylene succinate) polyesters remained semi-crystalline after quench cooling, with characteristic melting endotherms present at $\sim 95^{\circ} \mathrm{C}$ and $\sim 110^{\circ} \mathrm{C}$ for PESu and PBSu, respectively. In all cases, increasing polyesters' content resulted in a significant reduction of $\mathrm{T}_{\mathrm{g}}$ (compared to the pure PVA) as shown in Figure 8, indicating that all tested poly(alkylene succinate) polyesters may successfully act as plasticizers to PVA. 

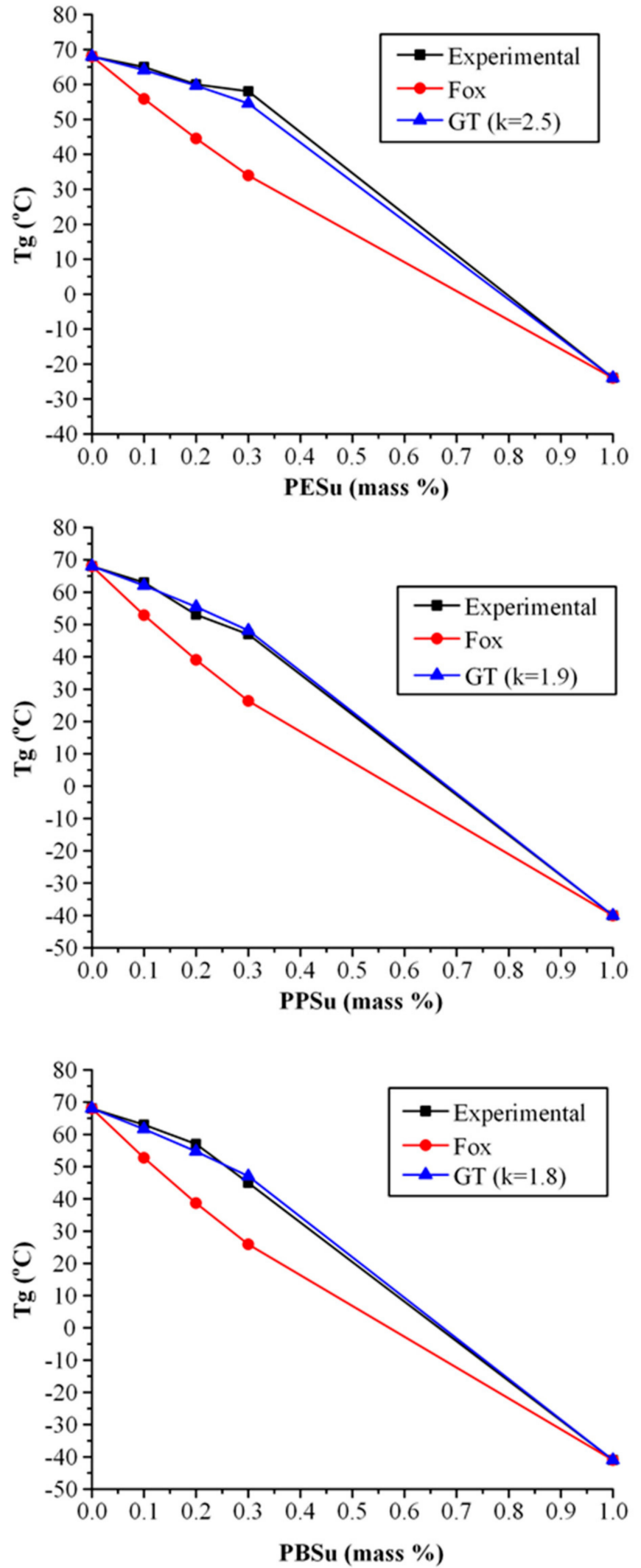

Figure 8. Prediction of $\mathrm{T}_{\mathrm{g}}$-composition dependence in PVA/polyester blends by using Fox and Gordon Taylor (GT) equations. 


\subsubsection{Physical State Evaluation}

Figure 9 shows the pXRD diffractograms of pure components along with the PVApolyester melt dispersions. In regard to PVA, pXRD revealed an amorphous halo along with a characteristic strong crystalline reflection at $2 \theta \sim 19.5^{\circ}$ and a shoulder at $\sim 22.6^{\circ}$, indicating the semi-crystalline nature of the polymer. In regard to the obtained poly(alkylene succinate) polyesters, results from the obtained pXRD diffractograms correspond to the known $\alpha$ crystal forms of these polyesters [48]. Regarding to the PVA-polyester melt dispersions, the obtained patterns showed that all PVA's characteristic $2 \theta$ reflections were present (i.e., at $\sim 19.5^{\circ}$ and $\sim 22.6^{\circ}$ ), revealing that, in all cases, PVA remained semi-crystalline after its processing with the selected low molecular oligomers of poly(alkylene succinate) polyesters. Additionally, except for PPSu, the diffractograms obtained from the melt dispersions showed some of the characteristic crystalline peaks of the polyesters, indicating that, in these cases, both PESu and PBSu remained semi-crystalline within the PVA matrix. Finally, in comparison to the rest polyesters, when PPSu was utilized as a plasticizer a significant reduction in the obtained PVA crystalline reflection peaks was observed, verifying DSC's findings that in the case of PPSu the crystallinity of the PVA is significantly reduced compared to PESu and PBSu.

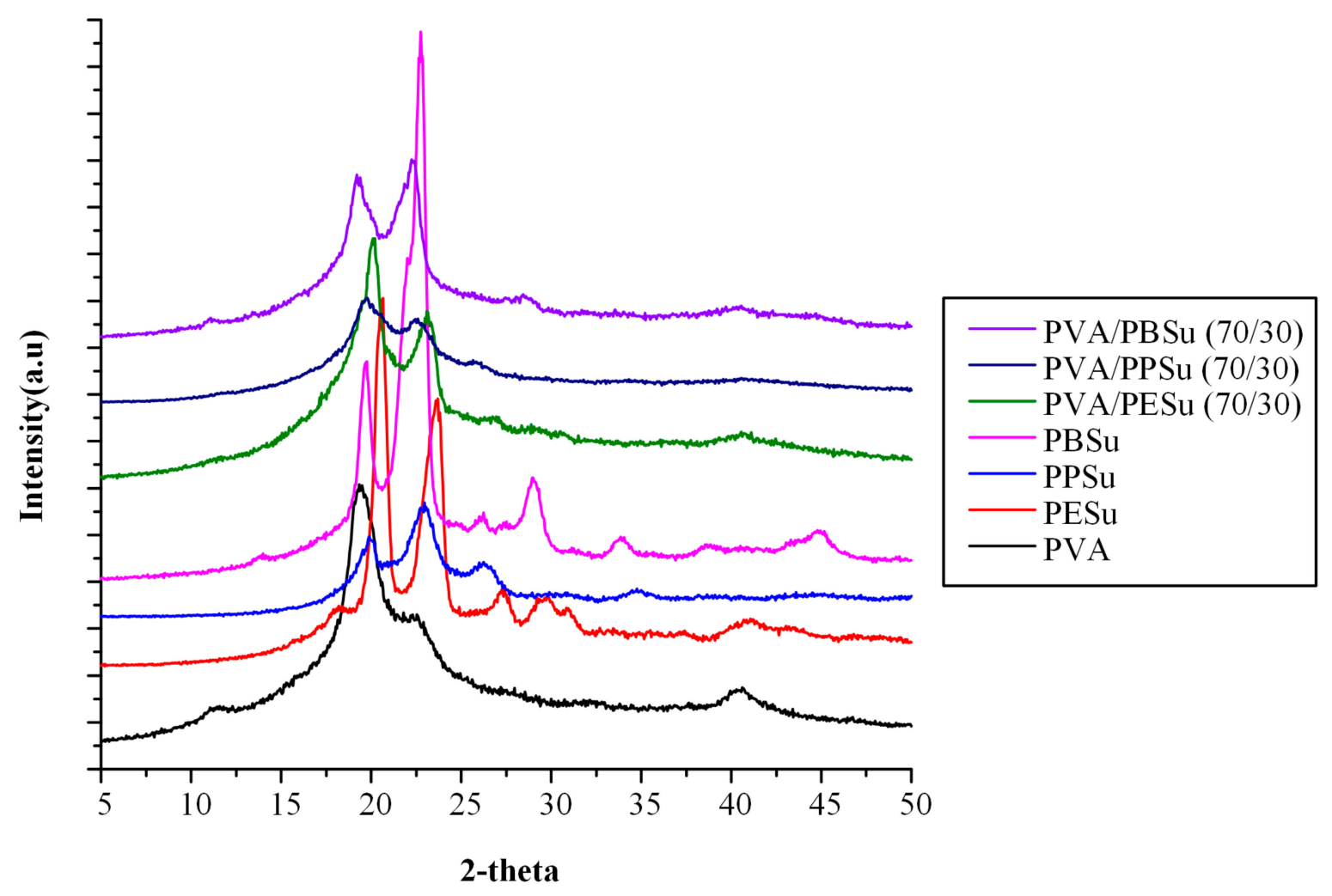

Figure 9. pXRD diffractograms of pure components and PVA-polyesters melt dispersions.

\subsubsection{Molecular Interactions}

In a further step, the formation of molecular interactions between PVA and the examined polyesters was evaluated both experimentally (via DSC and ATR-FTIR) and theoretically (via MD simulations).

\section{DSC Analysis}

The formation of molecular interactions between any two miscible compounds (such as a polymer and a plasticizer) may be investigated through DSC, by evaluating the dependence of the $\mathrm{T}_{\mathrm{g}}$ in regard to components' mass fractions. Until now, there are several 
theoretical and empirical equations describing this dependence. Among them, the Fox model expresses this relation with the following equation [49].

$$
\left[1 / \mathrm{T}_{\mathrm{g}}\right]=\mathrm{w}_{1} / \mathrm{T}_{\mathrm{g} 1}+\mathrm{w}_{2} / \mathrm{T}_{\mathrm{g} 2}
$$

where, $T_{g}$ is the glass transition temperature of the polymer-plasticizer blend, $\mathrm{w}_{1}$ and $\mathrm{w}_{2}$ are the mass fractions of the polymer and the plasticizer that constitute the blend and $\mathrm{T}_{\mathrm{g} 1}$ $\& \mathrm{~T}_{\mathrm{g} 2}$ are their respective glass transition temperatures.

Accordingly, Gordon and Taylor have proposed a similar equation taking into account the possibility of significant interactions evolving between the studied components [50]:

$$
\mathrm{T}_{\mathrm{g}}=\left(\mathrm{w}_{1} \mathrm{~T}_{\mathrm{g} 1}+\mathrm{kw}_{2} \mathrm{~T}_{\mathrm{g} 2}\right) /\left(\mathrm{w}_{1}+\mathrm{kw}_{2}\right)
$$

where, $\mathrm{k}$ is a constant representing a semi-quantitative measure of the interaction strength between the reactive groups. If $k$ takes values close to 1 or above then strong interactions between the miscible blend components are taking place $[37,51]$.

Figure 8 shows the experimental $\mathrm{T}_{\mathrm{g}} \mathrm{s}$ as well as the theoretical predictions based on the Fox and Gordon-Taylor (GT) approaches. Contrary to the Fox model (where the theoretically estimated $\mathrm{T}_{\mathrm{g}} \mathrm{s}$ were not in good agreement with the recorded experimental values) the theoretical predictions for $\mathrm{T}_{\mathrm{g}} \mathrm{s}$ according to GT equation, fit quite well to the experimental data, with $\mathrm{k}$ parameter being well above one in all cases (i.e., 2.5, 1.9 and 1.8 for PESu, PPSu and PBSu, respectively). This indicates that significant intermolecular interactions are taking place between the two components. However, although the combination of DSC data with theoretical modelling can reveal the presence of molecular interactions, this method does not provide any details regarding to the type of the interaction evolving. Hence, in order to do so, a more suitable method, such as the use of ATR-FTIR spectroscopy is needed.

\section{ATR-FTIR Analysis}

Figure 10 shows the ATR-FTIR spectra of pure components, PVA-polyesters physical mixtures (PMs) and melt-fusion dispersions (MFDs) at several ratios. The spectrum of pure PVA showed characteristic peaks at $3301 \mathrm{~cm}^{-1}$ (stretching of $\left.-\mathrm{OH}\right), 1724 \mathrm{~cm}^{-1}$ (stretching of $-\mathrm{C}=\mathrm{O}$ from the remaining acetyl groups), $1423 \mathrm{~cm}^{-1}$ (bending of $-\mathrm{OH}$ and wagging of $\left.-\mathrm{CH}_{2}\right), 1321 \mathrm{~cm}^{-1}\left(\delta(\mathrm{OH})\right.$ rocking with $\mathrm{CH}$ wagging), $1145 \mathrm{~cm}^{-1}$ (shoulder stretching of -CO- from the crystalline part of PVA) and $1083 \mathrm{~cm}^{-1}$ (bending of -OH from amorphous part of PVA). Regarding to the neat polyesters, the strong signals at $1717 \mathrm{~cm}^{-1}$ and $1155 \mathrm{~cm}^{-1}$ could be assigned to the $-\mathrm{C}=\mathrm{O}$ and $-\mathrm{COO}-$ asymmetric stretching vibrations, respectively, which demonstrated the presence of ester linkages. As for the peak at $2960 \mathrm{~cm}^{-1}$, it is attributed to the stretching vibration of $-\mathrm{CH}$ of the $-\mathrm{CH}_{2}$ group. In the case of PVA-polyester mixtures, results showed several differences between the ATR-FTIR spectra of the MFD samples and the corresponding PMs. Specifically, a significant reduction and widening was observed at $3301 \mathrm{~cm}^{-1}$, corresponding to the $-\mathrm{OH}$ stretching of PVA, while slight shifts (from $1730 \mathrm{~cm}^{-1}$ to $1710 \mathrm{~cm}^{-1}$ ) were also observed in the region of $1750-1600 \mathrm{~cm}^{-1}$, corresponding to the $-\mathrm{C}=\mathrm{O}$ and $-\mathrm{COOC}$ - stretching of the poly(alkylene succinate) polyesters. These differences indicate that significant molecular interactions (probably hydrogen bonds, HBs) between the hydroxyl hydrogens of PVA and the ester oxygens of the polyesters are being formed during the melt-fusion processing. 


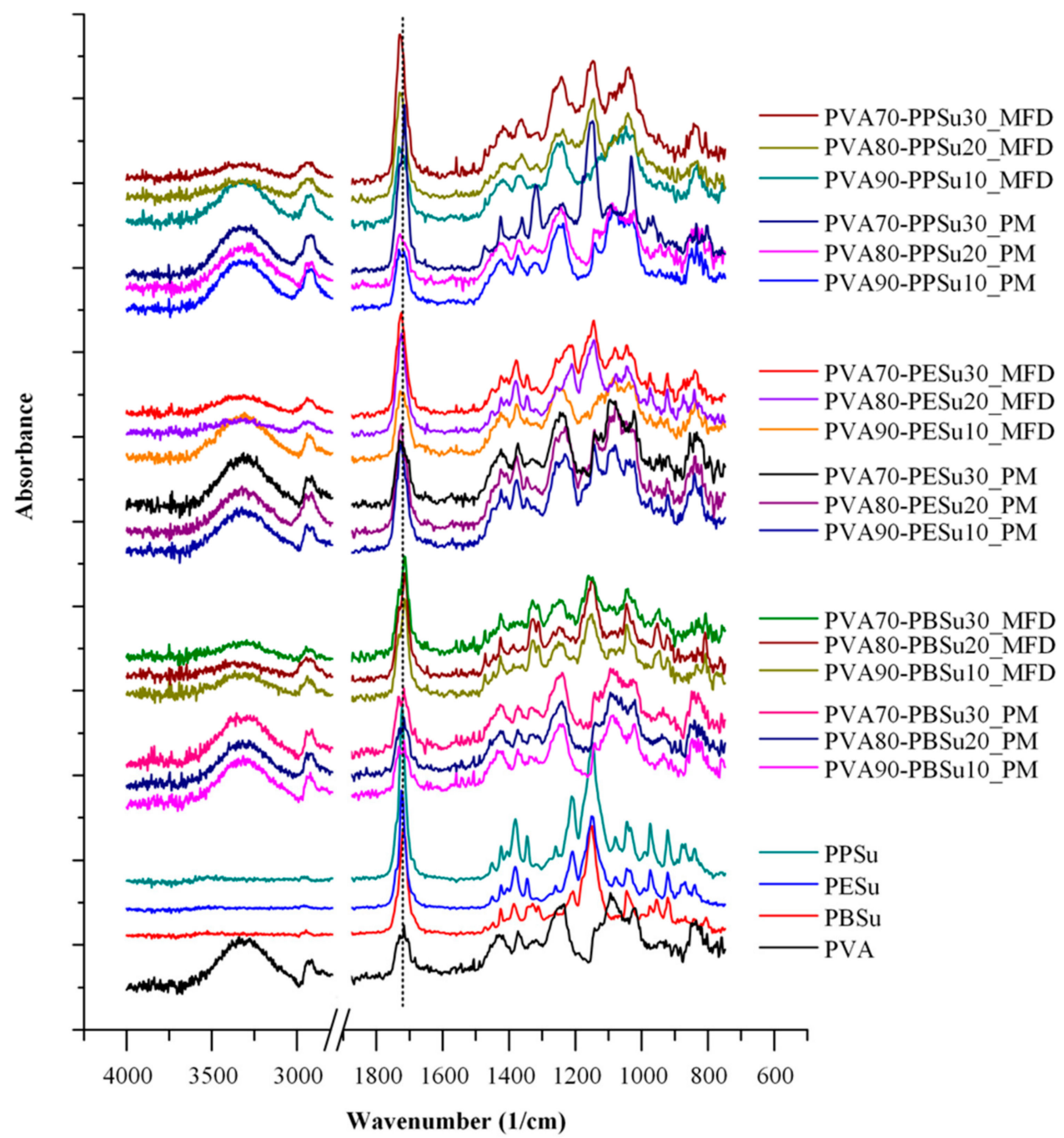

Figure 10. ATR-FTIR spectra of pure components and PVA-polyesters physical mixtures (PMs) and melt-fusion dispersions (MFDs).

\section{Simulations}

In addition to the above experimentally based approaches, an in-depth evaluation of the evolving molecular interactions was attempted with the aid of MD simulations. In general, MD simulations are able to provide detailed atomic-level structural and energetic information that can highly assist the investigation of such molecular interactions.

Figure 4 shows the MD molecular assemblies of the PVA and poly(alkylene succinate) polyester mixtures as resulted after the multistep equilibration protocol employed in the present study. Results showed that in all cases well mixed amorphous structures were constructed. Table 3 summarizes the total interaction energy between polyesters and PVA, estimated by MD simulations according to Equation (6). Results showed that the PVAPPSu exhibited the lowest interaction energy $(-2308 \mathrm{kcal} / \mathrm{mol})$ compared to PVA-PESu $(-2201 \mathrm{kcal} / \mathrm{mol})$ and PVA-PBSu $(-2274 \mathrm{kcal} / \mathrm{mol})$ mixtures, indicating that PVA-PPSu is the most stable systems. Additionally, this finding explains the complete amorphization of PPSu in the melted PVA samples, since strong interactions are being formed between the two components that restrict the polyester from re-crystallizing. 
Table 3. Interaction energy $\left(E_{\text {inter }}\right)$ of PVA-polyesters estimated via MD simulations.

\begin{tabular}{cc}
\hline PVA-Plasticizer & E $_{\text {inter }}$ (kcal/mol) \\
\hline PVA-PESu & -2201 \\
PVA-PPSu & -2308 \\
PVA-PBSu & -2274 \\
\hline
\end{tabular}

In a further step the molecular interactions between the prepared poly(alkylene succinate) polyester and the PVA matrices in the melt state were evaluated by generating the radial distribution functions, $g(r)$, between the hydrogen atoms of PVA and the oxygen atoms of polyesters (Figure 11). In such diagrams, donor-acceptor distances below $2.5 \AA$ can be characterized as strong interactions, while distances between $2.5-3.2 \AA$ and $3.2-$ $4.0 \AA$ are considered as moderate and weak interactions, respectively. Results showed the formation of a significant $g(r)$ peak at $2.09 \AA, 2.00 \AA$ and $2.08 \AA$ for PVA-PESu, PVA-PPSu and PVA-PBSu, respectively, indicating the presence of strong HBs between the hydroxyl hydrogens of PVA and the ester oxygens of all poly(alkylene succinate) polyesters. In addition, the obtained $g(r)$ results showed that PPSu forms slightly stronger HBs with PVA, since the peak for PPSu is slightly higher and located in a shorter $r$ distance than the rest polyesters.

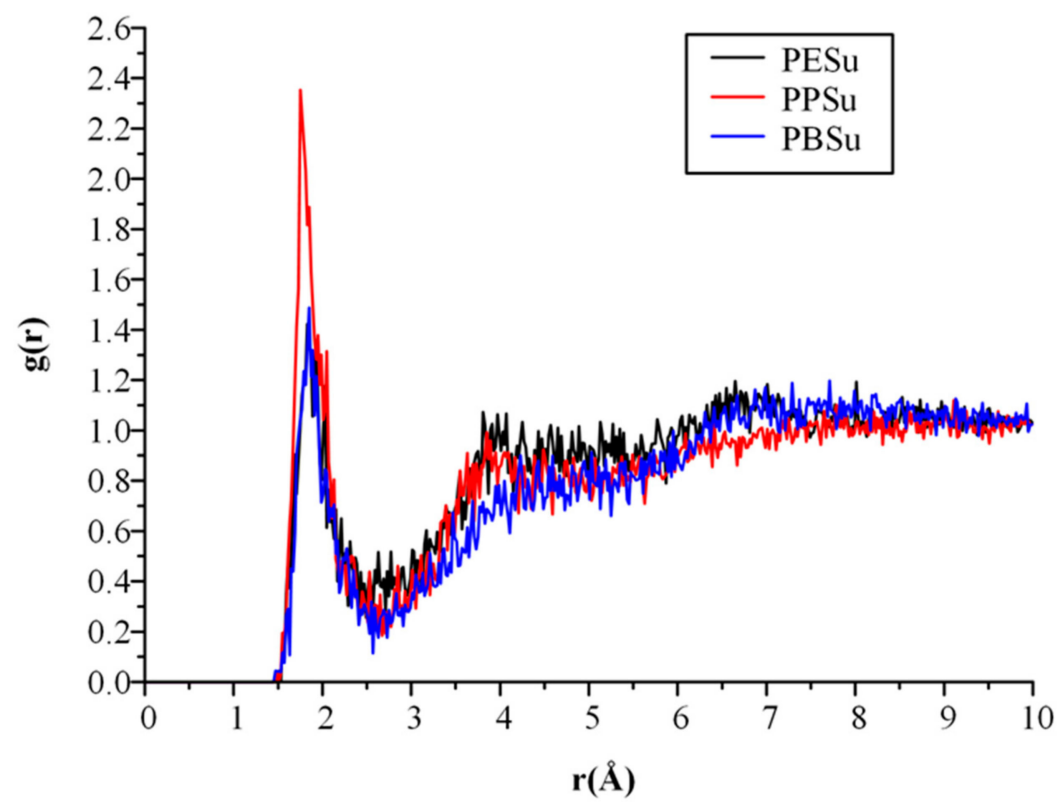

Figure 11. Radial distribution function, $g(r)$, between PVA's -OH proton hydrogen donor and polyester's oxygen acceptors.

\subsubsection{Melt Flow Properties}

In the final step of the present study, the effect of the selected polyesters on the melt flow properties of PVA was evaluated by measuring the MFI. In general, measurement of MFI is a common analytical method which is used as an indicator of the polymer's viscosity and the flow properties of the polymer melt at a certain temperature and applied pressure. Particularly, MFI is defined as the mass of the polymer extruded in ten minutes through an orifice of specific dimensions. The dimensions of the orifice, as well as the mass load and the temperature conditions are specified by ASTM D 1238 [52]. Although MFI is considered as the simplest, standardized measurement of the flowability of a polymer melt, it is not a fundamental polymer property. It is an empirically defined parameter critically influenced by the conditions of the measurement [53,54]. Nevertheless, it is suitable for quality control or comparative studies and it is still considered by the industry as a relatively cost-effective and quick analytical method to indicate the polymer's flow properties. Figure 12 shows the 
MFIs of pure PVA and PVA mixtures with 30 wt \%. PBSu, PESu and PPSu. Results showed that in all tested temperatures (with the exception of $210^{\circ} \mathrm{C}$ ) the addition of plasticizers resulted in higher MFIs, indicating better melt flowability, while a comparison of the MFIs for all PVA-polyesters mixtures, showed that PESu and PPSu had the greatest impact in terms of melt flow improvement.

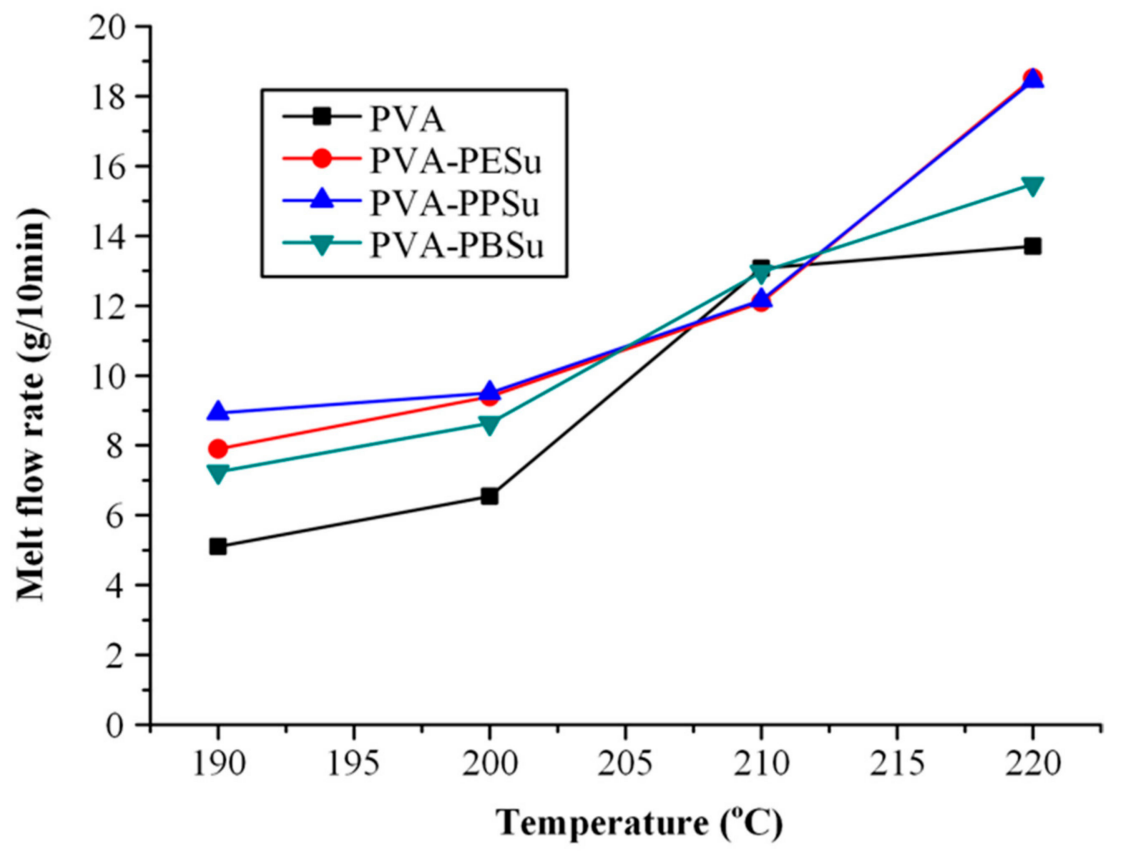

Figure 12. MFI vs. temperature for pure PVA and the PVA-polyesters mixtures.

\section{Conclusions}

The thermal degradation of PVA (which takes place almost immediately after its melting) as well as its significant processability problems at temperatures below its melting point, makes PVA's thermal treatment in pharmaceutical applications extremely difficult. Taking this limitation into consideration, in the present study three low molecular weight oligomers of poly(alkylene succinate) polyesters were synthesized and their efficacy as plasticizers for PVA fusion-based pharmaceutical applications was evaluated. According to the obtained results, all synthesized polyesters were miscible with PVA, while only PBSu and PPSu resulted in an acceptable thermal stability profile. It is important to note that the miscibility of the components was successfully predicted via MD simulations and was experimentally verified through HSM analysis. In addition, by using PPSu and PESu as plasticizers PVA's melt flow properties were improved. Afterwards, the utilization of ATR-FTIR spectroscopy revealed the formation of significant molecular interactions during melting in all tested systems, while the results obtained from the radial distribution function estimations showed that PPSu forms slightly stronger HBs with PVA. In conclusion, although a deeper insight into the prepared systems is still needed, the results of the present study indicate that PPSu may be a suitable plasticizer for reducing PVA's processing temperature without affecting its thermal decomposition profile.

Author Contributions: Conceptualization, P.B. and D.N.B.; methodology, A.P., A.K. (Afroditi Kapourani), E.C., P.A.K.; software, P.B., K.N.K.; formal analysis, A.P., A.K. (Afroditi Kapourani), E.C.; investigation, A.P., A.K. (Afroditi Kapourani), E.C., P.A.K.; resources, P.B., A.K. (Apostolos Kyritsis), D.N.B.; writing—original draft preparation, A.P., A.K. (Afroditi Kapourani), K.N.K.; writing-review and editing, K.N.K. D.N.B., P.B.; supervision, D.N.B., P.B.; project administration, D.N.B., P.B.; funding acquisition, D.N.B., P.B. All authors have read and agreed to the published version of the manuscript.

Funding: This research received no external funding. 
Institutional Review Board Statement: Not applicable.

Informed Consent Statement: Not applicable.

Data Availability Statement: Data is contained within the article.

Conflicts of Interest: The authors declare no conflict of interest.

\section{References}

1. Patil, H.; Tiwari, R.V.; Repka, M.A. Hot-Melt Extrusion: From Theory to Application in Pharmaceutical Formulation. AAPS PharmSciTech 2016, 17, 20-42. [CrossRef] [PubMed]

2. Beg, S.; Swain, S.; Rizwan, M.; Irfanuddin, M.; Malini, D.S. Bioavailability Enhancement Strategies: Basics, Formulation Approaches and Regulatory Considerations. Curr. Drug Deliv. 2011, 8, 691-702. [CrossRef] [PubMed]

3. Emami, S.; Siahi-Shadbad, M.; Adibkia, K.; Barzegar-Jalali, M. Recent advances in improving oral drug bioavailability by cocrystals. BioImpacts. 2018, 8, 305-320. [CrossRef] [PubMed]

4. Carrier, R.L.; Miller, L.A.; Ahmed, I. The utility of cyclodextrins for enhancing oral bioavailability. J. Control. Release. 2007, 123, 78-99. [CrossRef]

5. Vasconcelos, T.; Sarmento, B.; Costa, P. Solid dispersions as strategy to improve oral bioavailability of poor water soluble drugs. Drug Discov. Today. 2007, 12, 1068-1075. [CrossRef] [PubMed]

6. Van Duong, T.; Van den Mooter, G. The role of the carrier in the formulation of pharmaceutical solid dispersions. Part II: Amorphous carriers. Expert Opin. Drug Deliv. 2016, 13, 1681-1694. [CrossRef]

7. Tran, P.; Pyo, Y.-C.; Kim, D.-H.; Lee, S.-E.; Kim, J.-K.; Park, J.-S. Overview of the Manufacturing Methods of Solid Dispersion Technology for Improving the Solubility of Poorly Water-Soluble Drugs and Application to Anticancer Drugs. Pharmaceutics. 2019, 11, 132. [CrossRef]

8. Huang, S.; Williams, R.O. Effects of the Preparation Process on the Properties of Amorphous Solid Dispersions. AAPS PharmSciTech 2018, 19, 1971-1984. [CrossRef]

9. Mahmah, O.; Tabbakh, R.; Kelly, A.; Paradkar, A. A comparative study of the effect of spray drying and hot-melt extrusion on the properties of amorphous solid dispersions containing felodipine. J. Pharm. Pharmacol. 2014, 66, 275-284. [CrossRef]

10. Keen, J.M.; McGinity, J.W.; Williams, R.O., III. Enhancing bioavailability through thermal processing. Int. J. Pharm. 2013, 450, 185-196. [CrossRef]

11. Tiwari, R.V.; Patil, H.; Repka, M.A. Contribution of hot-melt extrusion technology to advance drug delivery in the 21st century. Expert Opin. Drug Deliv. 2016, 13, 451-464. [CrossRef] [PubMed]

12. Lin, X.; Hu, Y.; Liu, L.; Su, L.; Li, N.; Yu, J.; Tang, B.; Yang, Z. Physical Stability of Amorphous Solid Dispersions: A Physicochemical Perspective with Thermodynamic, Kinetic and Environmental Aspects. Pharm Res. 2018, 35, 125. [CrossRef] [PubMed]

13. Edueng, K.; Mahlin, D.; Bergström, C.A.S. The Need for Restructuring the Disordered Science of Amorphous Drug Formulations. Pharm. Res. 2017, 34, 1754-1772. [CrossRef]

14. Zhao, Y.; Xie, X.; Zhao, Y.; Gao, Y.; Cai, C.; Zhang, Q.; Ding, Z.; Fan, Z.; Zhang, H.; Liu, M.; et al. Effect of plasticizers on manufacturing ritonavir/copovidone solid dispersions via hot-melt extrusion: Preformulation, physicochemical characterization, and pharmacokinetics in rats. Eur. J. Pharm. Sci. 2019, 127, 60-70. [CrossRef] [PubMed]

15. Kapourani, A.; Vardaka, E.; Katopodis, K.; Kachrimanis, K.; Barmpalexis, P. Crystallization tendency of APIs possessing different thermal and glass related properties in amorphous solid dispersions. Int. J. Pharm. 2020, 579, 119149. [CrossRef] [PubMed]

16. Gaaz, T.S.; Sulong, A.B.; Akhtar, M.N.; Kadhum, A.A.H.; Mohamad, A.B.; Al-Amiery, A.A. Properties and Applications of Polyvinyl Alcohol, Halloysite Nanotubes and Their Nanocomposites. Molecules 2015, 20, 22833-22847. [CrossRef]

17. DeMerlis, C.C.; Schoneker, D.R. Review of the oral toxicity of polyvinyl alcohol (PVA). Food Chem. Toxicol. 2003, 41, 319-326. [CrossRef]

18. LaFountaine, J.S.; Jermain, S.V.; Prasad, L.K.; Brough, C.; Miller, D.A.; Lubda, D.; McGinity, J.W.; Williams, R.O. Enabling thermal processing of ritonavir-polyvinyl alcohol amorphous solid dispersions by KinetiSol ${ }^{\circledR}$ Dispersing. Eur. J. Pharm. Biopharm. 2016, 101, 72-81. [CrossRef]

19. Brough, C.; Miller, D.A.; Keen, J.M.; Kucera, S.A.; Lubda, D.; Williams, R.O. Use of Polyvinyl Alcohol as a Solubility-Enhancing Polymer for Poorly Water Soluble Drug Delivery (Part 1). AAPS PharmSciTech 2016, 17, 167-179. [CrossRef]

20. Thellen, C.; Cheney, S.; Ratto, J.A. Melt processing and characterization of polyvinyl alcohol and polyhydroxyalkanoate multilayer films. J. Appl. Polym. Sci. 2013, 127, 2314-2324. [CrossRef]

21. Alexy, P.; Káchová, D.; Kršiak, M.; Bakoš, D.; Šimková, B. Poly(vinyl alcohol) stabilisation in thermoplastic processing. Polym. Degrad. Stab. 2002, 78, 413-421. [CrossRef]

22. Wu, W.; Tian, H.; Xiang, A. Influence of Polyol Plasticizers on the Properties of Polyvinyl Alcohol Films Fabricated by Melt Processing. J. Polym. Environ. 2012, 20, 63-69. [CrossRef]

23. Jang, J.; Lee, D.K. Plasticizer effect on the melting and crystallization behavior of polyvinyl alcohol. Polymer 2003, 44, 8139-8146. [CrossRef]

24. Katopodis, K.; Kapourani, A.; Vardaka, E.; Karagianni, A.; Chorianopoulou, C.; Kontogiannopoulos, K.N.; Bikiaris, D.N.; Kachrimanis, K.; Barmpalexis, P. Partially hydrolyzed polyvinyl alcohol for fusion-based pharmaceutical formulation processes: Evaluation of suitable plasticizers. Int. J. Pharm. 2020, 578, 119121. [CrossRef] [PubMed] 
25. Yasuniwa, M.; Satou, T. Multiple melting behavior of poly(butylene succinate). I. Thermal analysis of melt-crystallized samples. J. Polym. Sci. Part B Polym. Phys. 2002, 40, 2411-2420. [CrossRef]

26. Papageorgiou, G.Z.; Bikiaris, D.N. Crystallization and melting behavior of three biodegradable poly(alkylene succinates). A comparative study. Polymer 2005, 46, 12081-12092. [CrossRef]

27. Karayannidis, G.P.; Roupakias, C.P.; Bikiaris, D.N.; Achilias, D.S. Study of various catalysts in the synthesis of poly(propylene terephthalate) and mathematical modeling of the esterification reaction. Polymer 2003, 44, 931-942. [CrossRef]

28. Bikiaris, D.; Karayannidis, G. Synthesis and characterisation of branched and partially crosslinked poly(ethylene terephthalate). Polym. Int. 2003, 52, 1230-1239. [CrossRef]

29. Solomon, O.F.; Ciută, I.Z. Détermination de la viscosité intrinsèque de solutions de polymères par une simple détermination de la viscosité. J. Appl. Polym. Sci. 1962, 6, 683-686. [CrossRef]

30. Breitkreutz, J. Prediction of Intestinal Drug Absorption Properties by Three-Dimensional Solubility Parameters. Pharm. Res. 1998, 15, 1370-1375. [CrossRef]

31. Pedretti, A.; Villa, L.; Vistoli, G. VEGA-An open platform to develop chemo-bio-informatics applications, using plug-in architecture and script programming. J. Comput. Aided Mol. Des. 2004, 18, 167-173. [CrossRef] [PubMed]

32. Sun, H.; Mumby, S.J.; Maple, J.R.; Hagler, A.T. An ab Initio CFF93 All-Atom Force Field for Polycarbonates. J. Am. Chem. Soc. 1994, 116, 2978-2987. [CrossRef]

33. Shenogin, S.; Ozisik, R. XenoView: Visualization for Atomistic Simulations. Available online: http://www.vemmer.org/ xenoview / xenoview.html (accessed on 15 September 2019).

34. Li, D.; Panchal, K.; Mafi, R.; Xi, L. An Atomistic Evaluation of the Compatibility and Plasticization Efficacy of Phthalates in Poly(vinyl chloride). Macromolecules 2018, 51, 6997-7012. [CrossRef]

35. Gunsteren, W.F.v.; Mark, A.E. Validation of molecular dynamics simulation. J. Chem. Phys. 1998, 108, 6109-6116. [CrossRef]

36. Macháčková, M.; Tokarský, J.; Čapková, P. A simple molecular modeling method for the characterization of polymeric drug carriers. Eur. J. Pharm. Sci. 2013, 48, 316-322. [CrossRef]

37. Papageorgiou, G.Z.; Bikiaris, D.N. Biodegradable poly(alkylene succinate) blends: Thermal behavior and miscibility study. J. Polym. Sci. Part B Polym. Phys. 2006, 44, 584-597. [CrossRef]

38. Bikiaris, D.N.; Papageorgiou, G.Z.; Papadimitriou, S.A.; Karavas, E.; Avgoustakis, K. Novel biodegradable polyester poly(propylene succinate): Synthesis and application in the preparation of solid dispersions and nanoparticles of a water-soluble drug. AAPS PharmSciTech 2009, 10, 138-146. [CrossRef]

39. Bikiaris, D.N.; Papageorgiou, G.Z.; Achilias, D.S. Synthesis and comparative biodegradability studies of three poly(alkylene succinate)s. Polym. Degrad. Stab. 2006, 91,31-43. [CrossRef]

40. Li, N.; Taylor, L.S. Nanoscale Infrared, Thermal, and Mechanical Characterization of Telaprevir-Polymer Miscibility in Amorphous Solid Dispersions Prepared by Solvent Evaporation. Mol. Pharm. 2016, 13, 1123-1136. [CrossRef]

41. Anderson, B.D. Predicting Solubility/Miscibility in Amorphous Dispersions: It Is Time to Move Beyond Regular Solution Theories. J. Pharm. Sci. 2018, 107, 24-33. [CrossRef]

42. Qian, F.; Huang, J.; Zhu, Q.; Haddadin, R.; Gawel, J.; Garmise, R.; Hussain, M. Is a distinctive single Tg a reliable indicator for the homogeneity of amorphous solid dispersion? Int. J. Pharm. 2010, 395, 232-235. [CrossRef] [PubMed]

43. Greenhalgh, D.J.; Williams, A.C.; Timmins, P.; York, P. Solubility parameters as predictors of miscibility in solid dispersions. J Pharm Sci 1999, 88, 1182-1190. [CrossRef] [PubMed]

44. Jankovic, S.; Tsakiridou, G.; Ditzinger, F.; Koehl, N.J.; Price, D.J.; Ilie, A.-R.; Kalantzi, L.; Kimpe, K.; Holm, R.; Nair, A.; et al. Application of the solubility parameter concept to assist with oral delivery of poorly water-soluble drugs-A PEARRL review. J. Pharm. Pharmacol. 2019, 71, 441-463. [CrossRef] [PubMed]

45. Kapourani, A.; Chatzitheodoridou, M.; Kontogiannopoulos, K.N.; Barmpalexis, P. Experimental, Thermodynamic, and Molecular Modeling Evaluation of Amorphous Simvastatin-Poly(vinylpyrrolidone) Solid Dispersions. Mol. Pharm. 2020, 17, 2703-2720. [CrossRef] [PubMed]

46. Yuan, X.; Sperger, D.; Munson, E.J. Investigating Miscibility and Molecular Mobility of Nifedipine-PVP Amorphous Solid Dispersions Using Solid-State NMR Spectroscopy. Mol. Pharm. 2014, 11, 329-337. [CrossRef] [PubMed]

47. Kapourani, A.; Vardaka, E.; Katopodis, K.; Kachrimanis, K.; Barmpalexis, P. Rivaroxaban polymeric amorphous solid dispersions: Moisture-induced thermodynamic phase behavior and intermolecular interactions. Eur. J. Pharm. Biopharm. 2019, 145, 98-112. [CrossRef]

48. Ihn, K.J.; Yoo, E.S.; Im, S.S. Structure and Morphology of Poly(tetramethylene succinate) Crystals. Macromolecules. 1995, 28, 2460-2464. [CrossRef]

49. Fox, T.G. Influence of Diluent and of Copolymer Composition on the Glass Temperature of a Poly-mer System. Bull. Am. Phys. Soc. 1956, 1, 123.

50. Gordon, M.; Taylor, J.S. Ideal copolymers and the second-order transitions of synthetic rubbers. i. non-crystalline copolymers. J. Appl. Chem. 1952, 2, 493-500. [CrossRef]

51. Eguiazabal, J.I.; Iruin, J.J.; Cortazar, M.; Guzmán, G.M. Glass transition temperatures in blends of poly(N-vinyl-2-pyrrolidone) with a copolymer of bisphenol A and epichlorohydrin or with poly(vinyl butyral). Die Makromol. Chem. 1984, 185, 1761-1766. [CrossRef] 
52. Ferg, E.E.; Bolo, L.L. A correlation between the variable melt flow index and the molecular mass distribution of virgin and recycled polypropylene used in the manufacturing of battery cases. Polym. Test. 2013, 32, 1452-1459. [CrossRef]

53. Dutta, A. On viscosity-melt flow index relationship. Rheol. Acta. 1984, 23, 565-569. [CrossRef]

54. Aho, J.; Boetker, J.P.; Baldursdottir, S.; Rantanen, J. Rheology as a tool for evaluation of melt processability of innovative dosage forms. Int. J. Pharm. 2015, 494, 623-642. [CrossRef] [PubMed] 